Portland State University

PDXScholar

1989

\title{
An Analysis of the Relationship Between Learning Style Perceptual Preferences and Attitudes Toward Computer-Assisted Instruction
}

Mary Brambilla McFarland

Portland State University

Follow this and additional works at: https://pdxscholar.library.pdx.edu/open_access_etds

Part of the Educational Methods Commons, and the Nursing Commons Let us know how access to this document benefits you.

\section{Recommended Citation}

McFarland, Mary Brambilla, "An Analysis of the Relationship Between Learning Style Perceptual Preferences and Attitudes Toward Computer-Assisted Instruction" (1989). Dissertations and Theses. Paper 1229.

https://doi.org/10.15760/etd.1228

This Dissertation is brought to you for free and open access. It has been accepted for inclusion in Dissertations and Theses by an authorized administrator of PDXScholar. Please contact us if we can make this document more accessible: pdxscholar@pdx.edu. 
AN ANALYSIS OF THE RELATIONSHIP BETWEEN LEARNING STYLE PERCEPTUAL PREFERENCES AND ATTITUDES TOWARD

COMPUTER-ASSISTED INSTRUCTION

by

MARY BRAMBILLA MCFARLAND

A dissertation submitted in partial fulfillment of the requirements for the degree of

\author{
DOCTOR OF EDUCATION \\ in \\ EDUCATIONAL LEADERSHIP
}

Portland state University

1989 
TO THE OFFICE OF GRADUATE STUDIES:

The members of the Committee approve the disserta-

tion of Mary Brambilla McFarland presented January 9, 1989.

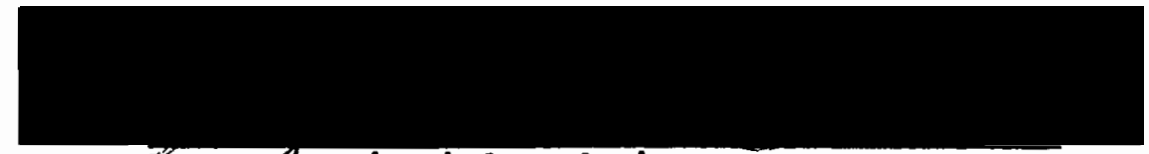

Kary Kinnick, Chairperson

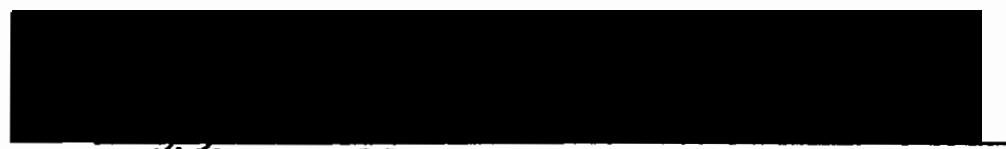

Jugith E. Allen
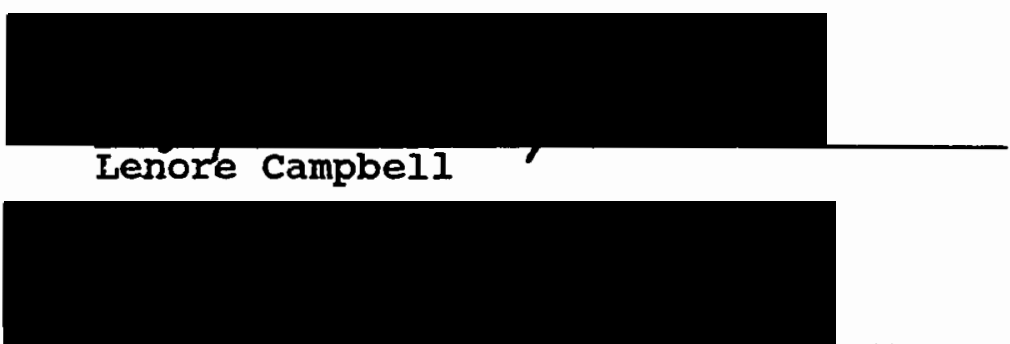

Barbara Gaines

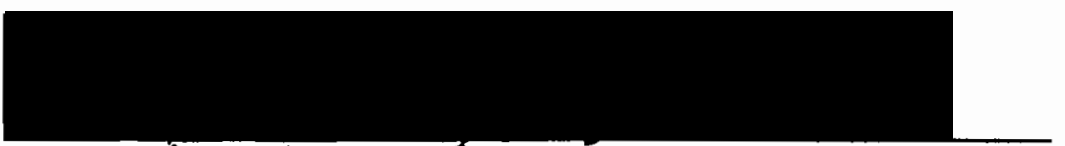

Michael R. Gaines

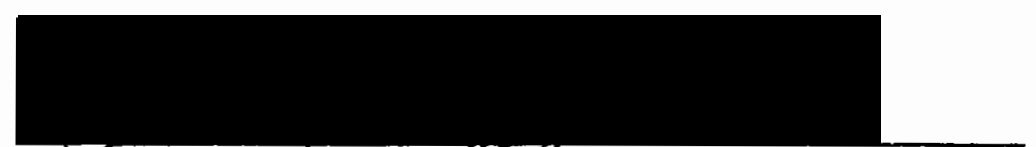

Harold C. Jorgfinsen

APPROVED:

Robert B. Everhart, Dean, School of Education

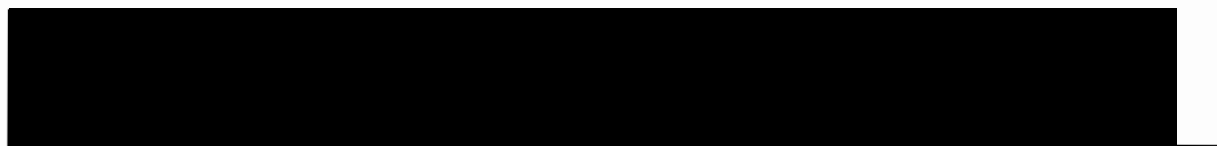

Bernard Ross, Vice Provost for Graduate studies 


\begin{abstract}
AN ABSTRACT OF THE DISSERTATION OF MarY Brambilla McFarland for the Doctor of Education in Educational Leadership presented January 9, 1989.

Title: An Analysis of the Relationship Between Learning style Perceptual Preferences and Attitudes Toward Computer-Assisted Instruction.
\end{abstract}

APPROVED BY THE MEMBERS OF THE DISSERTATION COMMITTEE:

Marl K. Kinnick, Chairperson

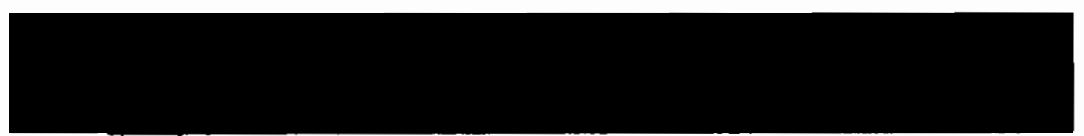

Juğith E. Allen
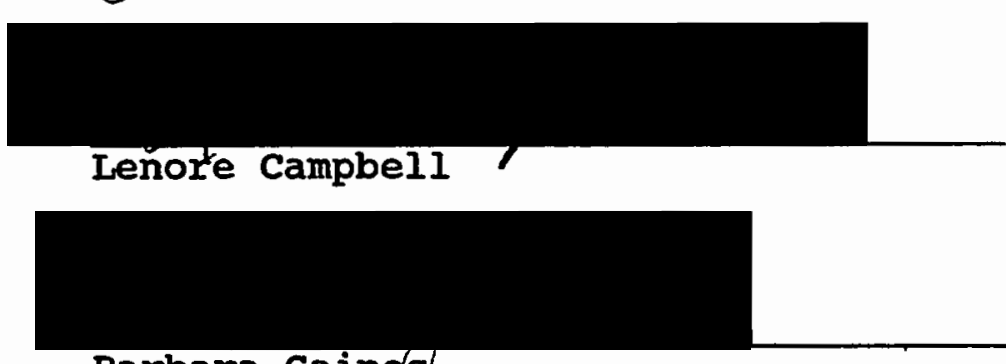

Barbara Gaines

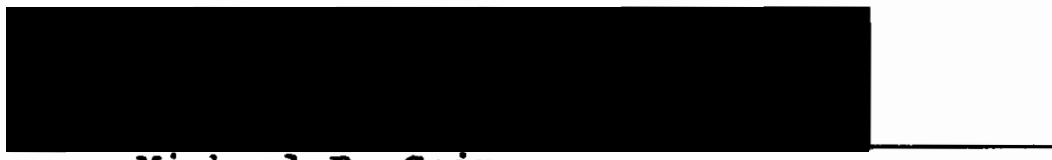

Michael R. Gaines

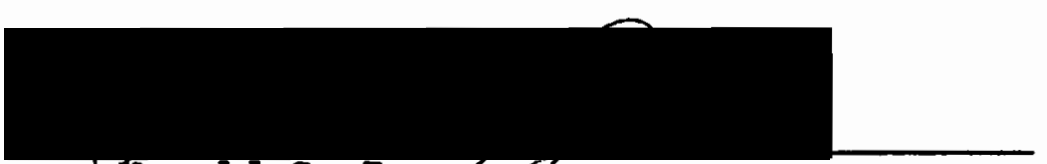

Garold c. Jorgengen 
The purpose of this investigation was to identify the perceptual learning style preferences of nursing students and to examine the relationship, if any, among students whose learning style perceptual preferences were identified as being auditory, tactile or visual and their attitudes toward the use of computer-assisted instruction (CAI) in the areas of comfort, creativity and function. The relationships between nursing students' perceptual learning style preferences and the following were also examined: (a) the amount of time they spent using the computer program, Cardiac Exam Bingo; (b) whether the use of the computer program added to their learning the content about the cardiac exam; and (c) whether the students wanted to have more use of computer-assisted instruction in the nursing program.

The data were collected using the Productivity Environmental Preference survey developed by Price, Dunn and Dunn (1986) and Allen's (1986) Attitude Toward CAI Semantic Differential scale. The study was conducted at a baccalaureate school of nursing in a health sciences university. The sample for the study was sophomore nursing students who were taking a nursing course in patient assessment.

Data were analyzed using the Pearson Product Moment Correlation and the Chi square statistic. All students, regardless of their perceptual learning style preference, had positive attitudes toward the use of computer-assisted instruction. Statistical analysis showed that there was no 
significant relationship between any one of the learning styles and students' attitudes toward CAI. Data analysis did show significant positive correlations between the amount of time students spent using the computer and the visual perceptual learning style; the attitude of function; whether students felt the use of the computer prograin added to their knowledge and whether they wanted more CAI added to the nursing curriculum.

Qualitative data were also gathered by asking students about their experience using the computer program, cardiac Exam Bingo. Comments about the use of computers in education indicated that students found the computer to be a useful study tool. Students did express concern that the use of CAI would add to students' work loads; therefore, they recommended that it be available to students but not required. Affective comments also provided further evidence that students had positive attitudes toward the computer program used for this study. 
ACKNOWLEDGEMENTS

I would like to express my appreciation and gratitude to the following people who provided support to me during the process that led to this achievement:

-To my chairperson, Mary Kinnick for her assistance, support and encouragement during every stage of this project.

-To Judy Edwards Allen, who introduced me to computer-assisted instruction, and planted the seed for this investigation.

-To Barbara Gaines who carefully reviewed this dissertation many times and willingly critiqued the application to nursing.

-To Len Campbell, Michael Gaines and Hal Jorgensen for their conscientious critiques of the drafts of this study and for their support as I moved toward its completion.

-To the sophomore students who willingly participated in this project during their busy spring quarter. -To Pati sluys who typed and typed, carefully and willingly.

-Above all I dedicate this dissertation to my son, stephen, for his love and affection and to my husband, Joe, 
whose encouragement, patience, understanding and love helped make this degree a reality. 
TABLE OF CONTENTS

PAGE

ACKNOWLEDGEMENTS • . . . . . . . . . . . . . . . . iii

LIST OF TABLES . . . . . . . . . . . . . . . . . viii

LIST OF FIGURES. • . • . . . . . . • . • . . . . . . xi

CHAPTER

I INTRODUCTION. . . . . . . . . . . . . . . . 1

Learning Styles and Teaching Methods. . . 6

The Importance of Identifying Learning Styles in College Teaching. . . . . 8

The Use of Computer-Assisted

Instruction in Schools of Nursing . . 11

statement of the Problem. . . . . . . 13

Definition of Terms . . . . . . . . 14

Limitations of the study. . . . . . . 16

II REVIEW OF THE LITERATURE. . . . . . . . . . 17

Introduction. . . . . . . . . . . 17

Learning styles . . . . . . . . . . 17

Comparison of Various Constructs. . . . 18

Learning Style Research . . . . . . 24

Review of Computer-Assisted

Instruction in Elementary and

Secondary Education. . . . . . . 29

The Effect of CAI on Achievement 
The Effect of CAI on Students' Attitudes

The Effect of CAI on Time spent

The Effect of CAI on Retention

Summary

Computer-Assisted Instruction at the

College Level . . . . . . . . . .

Achievement

Attitude/Achievement Correlation

Course Completion

student Attitudes

Instructional Time

Conclusions

The Use of Computer-Assisted Instruction in Schools of Nursing. . . . . . . 48

statement of Hypotheses . . . . . . . 62

setting . . . . . . . . . . . . 65

Sample. . . . . . . . . . . . . 66

Design. . . . . . . . . . . . . 66

Independent variable. . . . . . . . 67

Dependent Variable. . . . . . . . . 68

Method of Instruction . . . . . . . 69

Development Procedures. . . . . . . 69

Instruments . . . . . . . . . . 72

Productivity Environment

Preference study

student Attitude Survey

Statistical Methods . . . . . . . . 83

Distribution of Scores on the Perceptual Learning Style Preference . . . . .

Distribution of Scores for the Dependent Variables . . . . . . . 
vii

Perceptual Learning style Preferences and Student Attitudes Toward Computer-

Assisted Instruction. . . . . . . 88

Summary . . . . . . . . . . . . .

Student Responses to Open Ended questions . . . . . . . . . . . 101

The Computer Program Cardiac Exam Bingo

The Use of the Computer in Education

The Facilities (Instructional Media Department)

Affective Comments About Personal Learning

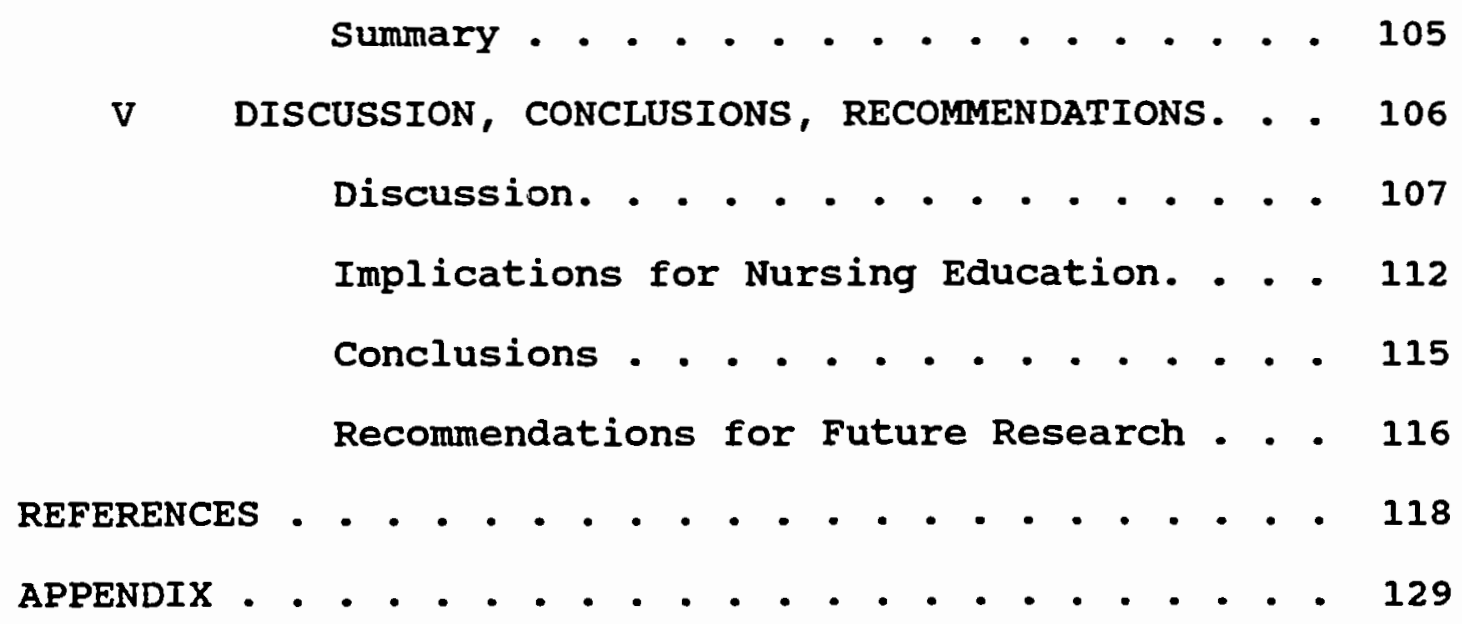




\section{LIST OF TABLES}

I The Effect of CAI on Achievement When Used as a Supplement to Traditional Education . . 33

II The Effect of CAI on Achievement When Used as a Substitute for Traditional Instruction.

III The Effect of CAI on student Attitudes Toward Subject Matter. . . . . . . . . 38

IV The Effect of CAI on the Amount of Time it Takes to Complete Course Material compared to Traditional Instruction .........

$V$ The Effect of CAI on Retention of course Material Learned . . . . . . . . . . . 41

VI Comparison of Nursing studies in Areas of student Achievement, student Attitudes, Instructional Time and other Findings. . .

VII Perceptual Preferences of 25 Nursing Students in the Auditory, Visual and Tactile Areas. . . . . . . . . . . . . .

VIII Students with a standard Score Equal to or Greater Than 60 in one or More Perceptual

IX Students with a standard score Equal to or Less Than 40 in one or More Perceptual

Preference Areas . . . . . . . . . . . .

$x \quad$ Students Whose Perceptual Preference in One or More Areas Were Between 0.5 and 1.0 Standard Deviation Above the Mean (Standard Score $=55-59$ ). . . . . . . . . . . . . 80

XI Mean and Standard Deviations for Perceptual Learning style Preferences Reported by Price, Dunn and Dunn (1982) for the PEPS. . . 86 
XII Mean and standard Deviations for Perceptual Iearning Style Preferences for 83 Nursing Students . . . . . . . . . . . . . . .

XIII Mean and standard Deviations for subjects' Attitudes in the Areas of Comfort, Creativity and Function . . . . . . . . . . .

XIV Mean and standard Deviations for the Amount of Time students spent Using the Computer Program; Whether the Use of the Computer Program Added to Their Knowledge and Whether they Wanted More Use of CAI in the Nursing Curriculum . . . . . . . . . . . . . 88

Correlation Matrix for Major Variables . .

XVI

Correlation Matrix for Time and Major

Variables. . . . . . . . . . . . .

XVII

Results of the Chi square Comparing student Perceptual Preferences to Students' Attitude, Comfort. . . . . . . . . . . . . . .

XVIII

Results of the Chi square Comparing student Perceptual Preferences to Students' Attitude, Creativity . . . . . . . . . . . . . . .

XIX Results of the Chi square comparing student Perceptual Preferences to Students' Attitude,

XX Results of the Chi Square comparing student Perceptual Preferences to students' Opinions About Whether the Use of Computer Program Added to Their Learning. . . . . . . . .

XXI Results of the Chi square comparing student Perceptual Preferences to Students' Opinions About whether They Wanted More CAI in the Curriculum . . . . . . . . . . . . . .

XXII Results of the Chi square Comparing student Perceptual Preference with the Amount of Time Spent Using the Computer Program When Time Was Divided Using the Mean and Standard Deviation. . . . . . . . . . . . . . . 
XXIII Results of the Chi Square Comparing student Attitudes Toward CAI with the Amount of Time Spent Using the Computer Program when Time was Divided Using the Mean and Standard Deviation.

XXIV Results of the Chi square Comparing students' Opinion About Whether Use of the computer Program Added to Their Learning and Whether They Wanted More CAI in the Curriculum with the Amount of Time Spent Using the Computer Program When Time was Divided Using the Mean and Standard Deviation . . . . . . . . . .

XXV Results of the Chi Square Comparing student Perceptual Preference with the Amount of Time spent Using the computer Program when Time was Divided into Two Groups . . . . . .

XXVI Results of the Chi Square Comparing student Attitudes Toward CAI with the Amount of Time Spent Using the Computer Program When Time was Divided into Two Groups . . . . . . . .

XXVII Results of the Chi square Comparing students' Opinion About Whether Use of the computer Program Added to Their Learning and Whether They Wanted More CAI in the Curriculum with the Amount of Time Spent Using the Computer Program When Time was Divided into Two

Groups . . . . . . . . . . . . . . .

XXVIII Results of the Chi square Comparing students Who scored in the Middle or High Ranges on Both the Visual and Tactile Perceptual Learning styles and Their Attitudes in the Areas of Comfort, Creativity and Function. . . .

XXIX Mean and Standard Deviations of the Attitudes of 83 Nursing students Toward CAI . . . . . 


\section{LIST OF FIGURES}

FIGURE

PAGE

1. Model for Instructional System Design . . . 71

2. Task Analysis for Cardiac Exam Bingo. . . 72

3. Flow Chart for Cardiac Exam Bingo . . . . 73 
CHAPTER I

\section{INTRODUCTION}

The use of computer technology has touched every aspect of our society from video games to the use of computers in business and industry. Computers have affected the way we play, the way we work and the way we educate our children. The widespread use of microcomputers has been enhanced by the reduction in their cost. In recent years, there has been a proliferation of microcomputers at the elementary, secondary and college levels across the nation. The rapid development of this technology is becoming so extensive that its potential influence in education appears to be limitless. Computer-assisted instruction (CAI) has been designed to enhance the education of students in the learning of facts, concepts and the higher level thinking required for problem solving. The use of computer programs has varied from being an elective supplement for traditional classroom lecture/discussions to being used as the primary vehicle for delivery of instruction. Because of the rapid changes being brought about by microtechnology, faculty members and students must understand the use of computers in education and be prepared to master and effectively use this new technology. 
It is possible that the use of computers may change the basic process by which students learn. Computers have the versatility to interface with other communication media which can provide improved individualized instruction and learning experiences to respond to the uniqueness of students' learning styles as well as to their personal interests.

In the past several years, there has been an increasing interest in student learning styles. This interest which began in elementary and secondary school settings has spread to higher education and specifically to schools of nursing. Some research has been done to determine the learning styles of nursing students; however, no research has been reported in the nursing literature that has examined the relationship between computer-assisted instruction and perceptual learning styles. In a practice profession such as nursing where new knowledge is increasing at a rapid rate, it is critical that we look at ways to improve the effectiveness of student learning.

Computers have been used to stimulate and reinforce student learning in a variety of ways. The drill and practice mode has been used to help students respond correctly to brief items presented in a format similar to flash cards. CAI has also been used to tutor students by helping them to understand new information by developing skill in using it. Branching options may be used based on student response to 
questions. Simulations and games have also been developed which help students experience a portion of reality and the interaction of complex relationships and events.

These different modes of computer-assisted instruction offer a variety of strategies to enhance the teaching process. Along with the advantage of offering different methods of instruction, CAI has advantages that are not available with traditional instruction. First, CAI offers immediate feedback to students of the results of their efforts. When students are actively involved in a simple drill and practice, or a complex simulation, they receive immediate feedback from the computer to their response. This type of feedback is often delayed when a student is involved with a real life situation. Second, the computer provides interactive learning to students. A well written program will respond to student answers offering information or help and guidance as needed. Third, the computer can overcome time restrictions that prevent individualizing instruction for all students. Again, a well written program provides one to one communication with students. They can progress at their own pace repeating parts or all of the program as often as they wish or need to in order to master the material presented. Fourth, CAI programs are more available to students than lecture periods or tutorial sessions with faculty members. Students who need to have 
more than one exposure to course content to fully understand it can benefit from the availability of computer programs. Computer-assisted instruction has been used in education since the late fifties and research studies to determine its effectiveness have been conducted since its inception. The contributions, impact and/or effectiveness of CAI reported in these studies have been summarized over the years by several authors. Kearsley, Hunter and Seidel (1983) reviewed more than fifty major research studies and programs conducted on CAI between 1959 and 1982. They adopted a broad definition of research which encompassed experiments, demonstrations, theory, innovation and invention. The authors noted that in spite of the limited scope and narrow selection of examples cited, their review documented the significant accomplishments which have been made in CAI effectiveness in the past twenty years. They expect an even greater impact on education in the future decades as CAI technology becomes more powerful, accessible and prevalent.

The studies reviewed by the authors offered convincing evidence that computers can make the learning experience much more exciting, satisfying and rewarding for the learner and teacher and do not stifle the creative process. They are not dehumanizing and do not foster antisocial development. However, the research also suggests that none of the potential benefits of CAI are inherent in this technology. 
They all depend upon the dedication, persistence and ability of teachers and courseware developers. The authors found that while CAI had reduced the dependence of instruction on the quality of human effort to some extent, such effort still remains the major factor in the successful or unsuccessful use of computers for education.

Several literature reviews were completed between 1972 and 1983 which attempted to determine the effectiveness of CAI. The studies reviewed looked at the effect of CAI on student achievement, attitudes toward the subject matter, time to complete course materials and the effect of CAI on the retention of material learned (Edwards, Norton, Taylor, Weiss, \& Dusseldorp, 1975; Jamison, Suppes, \& Wells, 1974 ; Kulik, Bangert, \& Williams, 1983; Rappaport \& Savard, 1980; Thomas, 1978; Vinsonhaler \& Bass, 1972; Wilson, 1980). These researchers found positive effects of CAI on achievement, attitude toward subject matter, the amount of time it takes to complete course requirements and retention. None of the studies reviewed focused on the relationship between learning styles and computer-assisted instruction.

The construct of learning styles has developed over the last several years and research suggests it may be a critical factor in designing learning environments. It is believed by some that each person learns in different ways; therefore, CAI may be better suited for some learners than others (Dunn \& Dunn, 1978). In fact, it is possible that 
students with different learning styles may have different achievement levels when using CAI and may also have different attitudes toward this method of learning. In 1985, Martini examined the relationships between perceptual learning style characteristics and computer-assisted instruction and the effects of matched and mismatched conditions on student achievement in science and attitudes toward each strategy. She found that CAI was significantly more effective for all students; attitude scores were consistently higher toward it and both achievement scores and attitude scores were significantly higher for all students in complementary instructional settings but tactually preferenced youngsters evidenced higher test scores than both other groups. Given the increase in the use of computer-assisted instruction and the importance of learning styles, it is critical that more is understood about their relationship.

LEARNING STYLES AND TEACHING METHODS

The diversity of learning styles among students has long been recognized in primary and to a lesser extent in secondary schools. In those settings, alternative instructional approaches have been designed to meet the needs of a wide variety of students. Dunn and Dunn (1979), after more than a decade of continuing research, state that most teaching methods work with some students but not with others. The researchers recognized that students who were successful 
with a particular method had essentially the same characteristics. The Dunns also reported that students at all levels who were taught using methods that complemented their learning characteristics became increasingly motivated and higher academic achievers than those who were not. This same result was found by Farr (1971) in her research with college students. There was significant improvement in both student achievement and motivation when learning and teaching methods were matched. Domino (1970) found a similar result among college students. In his study, those who had been exposed to a teaching method consonant with their perceived learning style scored higher on tests, fact knowledge, attitude and efficiency of work than those who had been taught in a manner dissonant with their orientation. It is unreasonable to expect college professors to attempt to match teaching methods with the learning styles of all of their students. However, they could supplement the popular whole-class lectures and discussions with alternative teaching methods. Dunn and Dunn assert that the elements of a student's learning style can be accommodated by any teacher regardless of learning style as long as the phenomena are understood and the teacher is willing to permit some flexibility. 
THE IMPORTANCE OF IDENTIFYING LEARNING STYLES

IN COLLEGE TEACHING

The college lecture has been the traditional method of college teaching since the middle ages. Clark Kerr (1976) has said: "You could go back to the University of Bologna in the 12th century and feel more or less at home." The effectiveness of the lecture method has been questioned for decades. In 1925, Charles Bane did research to determine the relative effectiveness of the lecture vs. class discussion methods of college teaching. In five experiments, students were given immediate recall tests at specific intervals. Delayed recall tests were given from one to six months after completion of the experiments. Bane found Iittle difference between the two groups on the immediate recall tests. However, on tests given one to six months later, consistent differences favored the discussion method. During the next several decades, similar studies were conducted. McKeachie (1967) noted that the results of most of the studies favored the lecture/discussion method over traditional lecture. He also pointed out that students learn as well from reading material as from listening to it. In fact, he found that better students profited more from reading than from listening to a lecture. Swartz (1980) has said:

Learning and teaching are separate processes; they can go on without each other, and often do. People learn from books, experiences, relationships, even their own thoughts. And others teach, explain, 
propound, while nobody learns or even listens. (p. 237)

The effectiveness of the traditional lecture methods of college teaching continues to be questioned by educational researchers. Kulik and Jaksa (1977) noted that major studies at Antioch College and the University of Colorado showed that the amount of time spent in college classrooms could be reduced by more than two-thirds without affecting end-of-course student achievement. Dubin and Taveggia (1968) concluded that students learned as much from independent study as they did from traditional approaches to college teaching. Their findings demonstrated that the conventional classroom lectures and discussions might be eliminated completely without altering student achievement. One reason for this conclusion may be that college teachers do not consider students' learning styles when planning their courses. In addition, there is a widely held belief that teachers either teach the way they were taught or the way they learn best (Freidman \& Alley, 1984).

The development of educational technologies has appealed to some educators as a way to improve the effectiveness of instruction. These included audio-tutorial systems, instructional television, programmed instruction, Keller's Personalized System of Instruction (PSI) and computer-assisted instruction (CAI). Although these technologies were found to be as effective as conventional teaching and in some cases resulted in superior end-of- 
course performance and in time savings for students (Kulik \& Jaksa, 1977), many of them are no longer used. One reason for this may be the lack of attention to student learning styles. When study results show that there is no difference in overall learning regardless of the teaching style used, teachers may not choose a variety of teaching methods, but use the one or more that they enjoy. Moreover, when student achievement is averaged, the differences in learning styles is lost.

During the past 20 years, there has been extensive research and writing about learning styles in the education literature (Canfield \& Lafferty, 1970; Dunn, 1982, 1983, 1984; Dunn \& Dunn, 1972, 1975, 1977, 1978, 1979; Dunn, Dunn, \& Price, 1976; Ehrhardt, 1983; Freidman \& Alley, 1984; Gregorc, 1979a, 1979b; Hill \& Nunney, 1974; Hunt, 1979; Keefe, 1982; Kolb, 1986; Lange, 1972; Millerick, 1983; Partridge, 1983; Smith \& Renzulli, 1984). Educators who have studied learning styles have been impressed with the increased achievement that resulted when students' unique characteristics are responded to in laboratory settings (Dunn, 1982). Carefully conducted research studies of students in primary and secondary grades have documented that teaching students through their individual learning styles results in the following behaviors: (a) increased academic achievement, (b) improved attitudes towards school and (c) reduced discipline problems (Dunn, 1982). While 
very little research on learning styles has been done on college students in general, it may aid the teaching/learning process in college classrooms if learning styles are considered when classes are developed.

Much of the research on the learning styles of nursing students has been done using the Kolb Learning style Inventory which measures personal and environmental variables. Several of the studies reported suggest that nurses and nursing students tend to have predominantly concrete learning styles as described by Kolb (Christiansen et al., 1979; Huch, 1981; Laschinger \& Boss, 1983; Marcinek, 1983; Seidman, 1983). Thus when this tool is used, little diversity among nursing students is reported. There are no studies reported in the literature that use a tool such as the Productivity Environmental Preference Survey (PEPS) developed by Price, Dunn and Dunn that assesses a multisensory approach to learning. If the diversity that exists in the learning styles of nursing students could be identified, faculty could plan their teaching strategies to match students' learning styles and increase the overall effectiveness of their teaching.

THE USE OF COMPUTER-ÄSSISTED INSTRUCTION IN SCHOOLS OF NURSING

The use of computers in schools of nursing to assist instruction has developed slowly. In the mid 1960s, some 
schools had terminals for student use. These terminals accessed a central computer. Most of these schools used the PLATO system which was expensive. Consequently, there were few research projects to demonstrate the effectiveness of computer-assisted instruction in the instructional process. The studies reported in the literature all had external funding sources and were carried out at institutions that had resources to use the PLATO system.

In 1966, a CAI project was described using a lesson titled "Care of the patient with a myocardial infarction." Results of the study showed that students in the experimental CAI group learned as well or better than those in the control group. In addition, the more active a student had been in the learning process, the more that was learned (Bitzer, 1966). This study led Bitzer and Boudreau to adapt a maternity nursing course for use on PLATO. Findings from this study indicated that the PLATo group retained more material than students in the control group (Bitzer \& Boudreau, 1969).

Another study examined the relationship among students' learning preference styles, attitudes, and performance on a CAI program using the PLATO system. The investigators found that all students learned the required material. Those students who scored high on an Active Experimentation (doing) scale also had high scores on learning. 
In the late 1970s, Huckabay et al. studied the effect of a simulation CAI program vs. lecture/discussion on nurse practitioner students studying the clinical management of the hypertensive patient. Results showed that there were no significant differences between the control and experimental groups in cognitive learning, transfer of learning or affective behavior. However, post-test scores on both types of learning showed that the experimental group had a significantly greater ability to transfer knowledge learned to patient situations (Huckabay et al., 1979).

The literature also contains descriptive articles that discuss how computers have been used in isolated nursing courses using the drill and practice mode (Schwartz \& Jackson, 1980; Timpke \& Janney, 1981) and patient simulations for purposes of evaluation (Olivieri \& Sweeney, 1980: Sumida, 1972). The findings in all of these studies suggest that there is considerable potential for use of CAI when teaching nursing students.

\section{STATEMENT OF THE PROBLEM}

As stated previously, there is no reported research on the perceptual learning style characteristics of nursing students using the PEPS developed by Price, Dunn and Dunn (1982). In addition, there is little research to date that examines the relationship between student satisfaction with 
computer-assisted instruction and perceptual learning style characteristics.

It was the purpose of this investigation to identify the perceptual learning style preferences of nursing students and examine the relationships, if any, among students whose learning style perceptual preferences are identified as being (a) auditory, (b) tactile, or (c) visual and their attitude toward the use of computer-assisted instruction. Specifically, an answer was sought to the following question: will there be positive correlations between students who have:

1. an auditory perceptual preference and negative attitudes toward CAI?

2. a visual perceptual preference and positive attitudes toward CAI?

3. a tactile perceptual preference and positive attitudes toward CAI?

\section{DEFINITION OF TERMS}

Learning style is the composition of characteristic cognitive, affective, and physiological factors that are considered relatively stable indicators of how a learner perceives, interacts with and responds to the learning environment. The pattern of behavior and performance by which an individual approaches educational experiences demonstrates that person's learning style. The structure of 
neural organization and personality which both molds and is molded by human development and the learning experiences of home, school and society is the basis of one's learning style (National Task Force, 1983).

Perceptual preference was identified by scores using the Productivity Environmental Preference Survey (PEPS) (Price, Dunn, \& Dunn, 1986). The learning style element of perceptual preference was measured by subjects' responses indicating their preferred perceptual mode (auditory, tactual or visual) for processing information (Dunn \& Dunn, 1979) .

- An auditory preference was evidenced by a score between 46 and 61 , as measured by the PEPS (Price, Dunn, \& Dunn, 1986) indicating that the subject preferred to process information when given precise, oral directions.

- A tactual preference was evidenced by a score between 48 and 60 , as measured by the PEPS (Price, Dunn, \& Dunn, 1986), indicating that a subject considered to be tactual was best able to remember what was learned through the use of hands-on materials.

- A visual preference was evidenced by a score between 44 and 55, as measured by the PEPS (Price, Dunn, \& Dunn, 1986), indicating that a subject considered visual preferences to learn through the use of resource that require reading and seeing. 
Computer-assisted instruction was the use of computers for the direct instruction of students. It was characterized by the interaction of students with computer terminals which present instructional material. In this study, the mode of computer-assisted instruction was tutorial.

\section{LIMITATIONS OF THE STUDY}

This study was limited by the characteristics of the participating sophomore nursing students enrolled in one school of nursing in the Pacific Northwest. It was further limited by the type of computer-assisted instruction used in this study. The computer program, Cardiac Exam Bingo, is a tutorial game designed for use with a specific course. students' attitudes toward the use of computer-assisted instruction might be different if the type of program or topic was different. 
CHAPTER II

REVIEW OF THE LITERATURE

\section{INTRODUCTION}

The purpose of this study was to determine the relationship between learning style perceptual preferences and computer-assisted instruction (CAI). Accordingly, the review of literature is organized into two sections. The first focuses on learning styles including a comparison of various constructs and learning style research and the second on a review of the use of computer-assisted instruction in elementary and secondary education, at the college level and in schools of nursing.

\section{LEARNING STYLES}

There is agreement among various researchers that individuals have different preferences for the way they learn (Dunn \& Dunn, 1975; Gregorc, 1979b; Hill \& Nunney, 1974; Kolb, 1986). During the 1970s, several learning style constructs were developed (Dunn \& Dunn, 1984). Investigators used a variety of definitions, models, instruments and techniques. Dunn and Carbo (1981) noted that while the models differed, many strands among them revealed essential similarities and were mutually supported. 
COMPARISON OF VARIOUS CONSTRUCTS

Researchers in the area of learning styles have centered the focus of their definitions and subsequent applications in a variety of ways. Canfield and Lafferty (1970), Gregorc (1979a), and Kolb (1986) characterized learning style by examining behavior and how people relate to their environment. Canfield and Lafferty described six dimensions from which learning style is derived. These were: (a) academic conditions (relations with instructor and peers), (b) structural conditions (organization and detail), (c) achievement conditions (goal setting and competition), (d) content taught (numbers, words, etc.), (e) preferred learning mode (listening, reading, ionic or direct experience), and (f) performance level expectations (superior through satisfactory). Their instrument, the Learning style Inventory, was designed to help teachers understand students' difficulties in completing academic units as well as for counseling students.

The model developed by Kolb (1986) characterized learning style as the consequence of hereditary traits, past experiences and the demands of the present environment to produce preferences for one of the following learning models: (a) Concrete Experience (CE), (b) Reflective Observation (RO), (C) Abstract Conceptualization (AC), and (d) Active Experimentation (AE). Kolb believed that 
instructional experiences should be designed to enhance individual strengths and encourage the development of nondominant preferences.

Another researcher who examined behavior was Gregorc $(1979 b)$. He looked at learning style from a phenomonological point of view. He believes it consists of distinctive observable behaviors that provide clues to the functioning of peoples' minds and how they relate to the world. In his analyses, he noted that people learn in a combination of dualities which are: (a) concrete/sequential--the ability to derive information through direct, hands-on experiences; (b) concrete/random--the ability to process ideas quickly and make intuitive leaps in exploring unstructured problemsolving situations; (c) abstract/sequential--characterized by excellent decoding abilities with written, verbal and image symbols; or (d) abstract/random--the ability to give attention to human behavior and to sense and interpret vibrations.

Hunt (1979) took a different focus than Canfield and Lafferty, Kolb and Gregorc. Instead of focusing on an individual's behavior, he described students in terms of the educational systems under which students were most likely to learn. He limited the construct of learning styles to the amount of external structure each person required. Degrees of structure were determined by using two instruments. The first, The Teacher Assessment of student Learning styles, 
focused on observations made based on student reactions to systematic, teacher-introduced changes in structure. The second instrument, Paragraph Completion Method, was a semiprojective method which assessed students' conceptual level by having them write responses to a posed topic.

Field dependence and field independence and the existence of cultural differences were the characteristics Ramirez and Castaneda (1974) believed created individual learning styles. They believed learning style was not permanently fixed. Therefore, their objective was to help students achieve bicognitive ability so that they would not favor one learning style over another.

Schmeck, Ribich, and Ramanaiah (1977) like Ramirez and Castaneda (1974) viewed learning style as the product of the organization of a group of information processing activities that individuals prefer to engage in when confronted with a learning task. Those activities include Deep Processing (the extent to which a student critically evaluated, conceptually organized, compared and contrasted information being studied), Elaborative Processing (concrete associations or examples from one's own experiences and application of that information to their own lives), Fact Retention (the process and storage of details and specific pieces of information regardless of any other processing strategies employed), and Methodical study (frequent and more careful study utilizing 
methods similar to the systematic techniques recommended by study manuals).

Among the many different researchers looking at learning styles, two models were developed which did not have a single dimension only, one by Hill and Nunney (1974) and one by Dunn and Dunn (1972). These models viewed learning style as a multidimensional set of variables that interacted to affect how students learn. Hill described a cognitive style map which was produced as a result of the many ways each individual seeks meaning. Hill defined cognitive style as the unique way in which an individual searched for meaning in three areas: (a) qualitative manipulation of theoretical symbols, (b) the cultural influences to which the individual had been exposed and which affected the meaning given to the qualitative and quantitative symbols provided, and (c) the meaning which the individual derived from the symbols which were perceived. Hills' Cognitive style Mapping identified strengths and weaknesses through those three stimuli. From this construct, a cognitive style model, the Modified Hill Model, was developed which presents a graphic picture of learning preference. This model has been used in schools, medical settings, post graduate training and patient instruction. Researchers using this model have found that knowledge and cognitive style is effective in improving academic achievement and person-to-person communication (Ehrhardt, 1983). 
A multisensory approach to learning in the instructional environment was developed by Dunn and Dunn (1972). They first identified 12 elements of learning style that they had observed and examined in classrooms. By 1975, when they published their first instrument, the Learning style Questionnaire, they had added six more to extend the number to 18. These were divided into four stimulus classifications with subcategories: (a) environmental (Sound, Light, Temperature, and Design), (b) emotion (Motivation, Persistence, Responsibility, and the need for either structure or options), (c) sociological (learning with Peers, Self, Pairs, Teams, Adults or in a Variety of ways), and (d) physical (Perceptual strengths or weaknesses, need for Intake, Time of day, energy levels and the need for Mobility). A fifth dimension, the psychological (Global/Analytic, Field Dependence/Independence, and Impulsive/Reflective) was included in 1979. Cerebral Preference was added and Field Dependence/Independence was deleted in 1981. The three psychological variables were incorporated into simultaneous and Successive Processing. In 1979, Kirby noted that the Learning style Inventory (ISI) developed by Dunn, Dunn and Price had established impressive reliability and construct validity. By 1982, Keefe reported that the LSI was the most widely used assessment instrument in elementary and secondary schools. Following development of the LSI, the Productivity Environmental Preference Survey (PEPS) was 
developed by identifying research variables that appeared to describe the ways adults prefer to work or learn. The area descriptors of the PEPS are identical to those of the LSI with the exception of Parent Figure Motivated and Teacher Motivated which are omitted from the PEPS. Reliability and construct validity data are described by Price, Dunn and Dunn (1982) in the PEPS Manual.

The similarities of the various models have been summarized by Dunn, DeBello, Brennan, Krimsky and Murrain (1981):

Although these researchers seem to be reporting different characteristics, closer examination reveals that the models overlap in many ways. For example, the element of structure is addressed by Canfield and Lafferty; Dunn, Dunn, and Price; Gregorc; Hill; Hunt; and Ramirez and Castaneda. Motivation and sociological needs are included in descriptions by Canfield and Lafferty; Dunn, Dunn, and Price; Gregorc; Hill; and Ramirez and Castaneda. Perceptual modes are incorporated into the work of Canfield and Lafferty; Dunn, Dunn and Price; Gregorc; Hill; Hunt; and Kolb. And, thought processing is involved by Canfield and Lafferty; Gregorc; Hill; Kolb; Ramirez and Castaneda; and Schmeck. (p. 372)

The use of the Learning style Inventory: Primary (LSI:P) (Perrin, 1982), the Learning style Inventory (LSI) (Price, Dunn, Dunn, 1983), and the Productivity Environmental

Preference Survey (PEPS) (Price, Dunn, \& Dunn, 1981) affords administrators a comprehensive grade level continuum unavailable in other diagnostic instruments. Price, Dunn and Dunn instruments, in contrast to previously mentioned tools, include the greatest number of learning style 
characteristics. Although these instruments lack a clearly defined cognitive domain and may be more idiosyncratic than practical in some of their elements, those analyses concern only one or two elements. All three still are relatively young instruments and are among the best available (Freeley, 1984). The Learning style Inventory is a practitioneroriented instrument with commendable validation and widespread application, particularly in elementary schools (Keefe, 1982, p. 53). By 1985, it had well established its predictive validity (DeBelo, 1985, Della Valle, 1984; Hodges, 1985; Krimsky, 1982; Kroon, 1985; Lynch, 1981; MacMurren, 1985; Murrain, 1983; Pizzo, 1982; Shea, 1983; Virostko, 1983; White, 1981). Dunn, Dunn and Price used the Learning style Inventory model to develop the Productivity Environmental Preference survey for use with adults.

\section{LEARNING STYLE RESEARCH}

Several studies have been done to determine the relationship between learning styles and academic achievement. The primary question to be answered was whether academic achievement could be increased if students' learning styles were known. Most of the subjects for the studies were in grammar or middle school grades.

In 1977, Kaley examined the emotionai element of learning styles. She reported that among her population of sixth grade children, reading achievement was statistically 
stronger and a more efficient predictor of learning style than I.Q. She also noted that children with a high reading level had a more independent learning style than children with a lower reading level.

Three years later, wingo (1980) examined the relationship among locus of motivation, sensory modality characteristics and sociological grouping preferences with minimum competency test performance in 176 eighth graders. The Dunn, Dunn and Price Learning style Inventory was used. study results showed that the only learning style element that significantly correlated with high reading achievement was a preference for learning alone. The next best predictor of high reading scores was a preference for learning with one peer.

Murray's study done in 1980 expanded the work of Kaley (1967) and wingo (1980) by examining the relationships between high and low reading achievement and learning style. The Learning Style Inventory was administered to 122 seventh grade students. The results indicated that high reading achievers were more self-activated and more responsible than the poor achievers. They also preferred to learn alone. This characteristic was also found to be true in wingo's study.

Several of the elements in each of the five stimulus classifications identified by Dunn, Dunn and Price have been analyzed in experimental studies. Urbschat (1977) examined 
the value of teaching through perceptual strengths in a population of 135 first grade students from crosssocioeconomic backgrounds and with I.Q.S ranging between 90 and 110. The group was divided into visual, auditory or auditory/visual learners. At that time, researchers had not yet begun to focus on the tactual or kinesthetic elements. Consonant/Vowel/Consonant trigrams were presented to each subgroup by either an auditory, visual or auditory/visual method. The results of this study showed that (a) modality strengths could be identified among first graders, (b) superior and significant results occurred when a treatment was matched to each youngster's appropriate modality, and (c) most first graders in the study found it easier to learn through either a visual or a combined auditory/visual approach than solely through an auditory treatment. The outcomes of this study revealed the value of providing visual methods for introducing reading rather than the traditional phonics (auditory) approach.

The reading process was also the focus of the studies of both Carbo (1980) and Wheeler (1983). Carbo examined the teaching of reading through perceptual strengths. When students were taught through approaches congruent with their strongest modality, significant increases in reading scores resulted. Visually preferenced children had the best results with word recognition treatments; however, similar differences in scores were not seen among auditory or 
tactual children. Wheeler (1983) identified the strongest modality of 15 learning disabled second grade students who were reading at least two years below grade level. Each youngster was taught ten, randomly selected words through three different instructional methods; auditory, visual or tactual. No significant differences were found between the scores of students with selected perceptual strengths; however, all increased their performance whenever their perceptual strengths were matched with complementary sensory approaches to reading.

Additional elements of the Dunn and Dunn learning style model have been examined by Krimsky (1982), Lynch (1981) and White (1981). Utilizing the Learning style Inventory and the California Psychological Inventory, White looked at the elements of persistence and responsibility. She reported that subjects who exhibited high persistence and responsibility achieved significantly higher test scores than students with low persistence and responsibility. Lynch (1981) investigated another element of the Dunn and Dunn learning style model. Scheduled academic classes with students' individual learning style preferences were matched with the element of time. A sample of 136 eleventh and twelfth grade students were diagnosed for their preferences for time and then were matched or mismatched with those and their English teacher assignments and time preferences for the duration of the study. The number of truancy units were 
then assessed. The findings showed that (a) when matched for time preference and mismatched for teacher assignment, chronic truants attended more frequently; (b) there was a significant interaction among degree of truancy, learning style time preference and English teacher assignment, which suggested that time preference was a crucial factor in the reversal of patterns of truancy; and (c) initial truants attended less frequently when assigned to the same English teacher for two consecutive years. The results of this study suggest that time preference is apparently crucial to student behavior and attendance.

Krimsky (1982) examined students' learning style preferences for light. Children with an identified preference for either bright or low light when learning were randomly divided into two treatment groups. A reading achievement test was given to those groups under lighting conditions which either matched or mismatched their preferences. Scores on both reading speed and accuracy were consistently higher when the illuminated instructional environment matched the child's diagnosed learning style preference for light. Both groups performed statistically less well when tested in mismatched environments. No significant difference was evidenced in reading speed or accuracy between children with learning style preferences for either bright or low light. 
The Learning style Inventory was also used by Kroon (1985) who identified the perceptual strengths of ninth and tenth grade industrial arts students. Every student was presented with six lessons--two auditory, two visual and two tactual. Achievement tests administered after each treatment revealed that lessons matched to the subject's perceptual preference resulted in statistically higher test scores. Achievement was significantly increased further when new information was introduced through individuals' strongest perceptual preferences, and then reinforced through secondary or tertiary preferences.

The research studies reviewed here confirm the relationship of learning styles to behavior, academic achievement and improved attitudes toward learning. When learning styles were congruent with the instructional program, achievement was significantly greater than for subjects who were placed in incongruent settings. In the studies cited, results were consistent for those elements in each of the five stimulus classifications identified by Dunn and Dunn (1978).

REVIEW OF COMPUTER-ASSISTED INSTRUCTION IN ELEMENTARY AND SECONDARY EDUCATION

Computer-assisted instruction has been used in education since the late fifties and research studies to determine its effectiveness have been conducted since its 
inception. The contributions, impact and/or effectiveness of CAI reported in these studies have been summarized over the years by several authors. Kearsley, Hunter and Seidel (1983) reviewed more than fifty major CAI research studies and programs conducted on CAI between 1959 and 1982. They adopted a broad definition of research which encompassed experiments, demonstrations, theory, innovation and invention. Nine major findings were identified. These were:

1. There is ample evidence that computers can make instruction more efficient or effective.

2. We know relatively little about how to individualize instruction.

3. We do not have a good understanding of the effects of instructional variables such as graphics, speech, motion or humor.

4. A great deal has been learned about overcoming instructional and organizational inertia and resistance to change in the context of implementing CAI.

5. Significant progress has been made on the development of authoring tools and techniques for CAI.

6. Numerous mechanisms have been developed for the dissemination of CAI ideas and courseware.

7. CAI has spurred research throughout the entire field of instruction.

8. Federal funding has played a pivotal role in advancing CAI. 
9. We have just scratched the surface of what can be accomplished with computers in education.

The authors note that in spite of the limited scope and narrow selection of examples they cited, their review documents the significant accomplishments which have been made in CAI research in the past twenty years. They expect an even greater impact on education in the future decades as CAI technology becomes more powerful, accessible and prevalent.

The studies reviewed by the authors showed that computers can make the learning experience much more exciting, satisfying and rewarding for the learner and teacher and do not stifle the creative process. They are not dehumanizing and do not foster antisocial development. However, the research also suggests that none of the potential benefits of CAI are inherent in this technology. They all depend upon the dedication, persistence and ability of teachers and courseware developers. The authors found that while CAI has reduced the dependence of instruction on the quality of human effort to some extent, such effort still remains the major factor in the successful or unsuccessful use of computers for education.

Several literature reviews were completed between 1972 and 1983 which attempted to determine the effectiveness of CAI. The studies reviewed looked at the effect of CAI on student achievement, attitudes toward the subject matter, 
time to complete course materials and the effect of CAI on the retention of material learned (Edwards et al., 1975; Jamison et al., 1974; Kulik, Bangert, \& Williams, 1983; Rappaport \& Savard, 1980; Thomas, 1978; Vinsonhaler \& Bass, 1972; Wilson, 1980).

The Effect of CAI on Achievement

All of the authors found that CAI has a positive effect on student achievement when used as a supplement for traditional instruction. Six review articles covered 162 studies, 137 of which indicated a positive effect, 17 with no effect and 8 with inconclusive results (see Table I). The effect on achievement when CAI was used as a replacement for traditional instruction was not clear. Two reviews of 21 studies of the use of CAI as a substitute reported that 10 indicated a positive effect and 11 were inconclusive (see Table II).

Vinsonhaler and Bass (1971) found that student achievement on standardized tests indicated that CAI was more effective than traditional instruction in drill and practice for mathematics and language arts. Generally, CAI groups showed performance gains of one to eight months over groups receiving traditional instruction.

At the elementary school level, CAI seemed to be as effective when used as a supplement to regular instruction. At the secondary school and college levels, a conservative 
conclusion was that CAI was about as effective as traditional instruction when it was used as a replacement (Jamison et al., 1974).

TABLE I

THE EFFECT OF CAI ON ACHIEVEMENT WHEN USED AS A SUPPLEMENT TO TRADITIONAL EDUCATION

$\begin{array}{llll} & \text { *Studies cited } & \text { Studies cited } & \text { Studies cited } \\ \text { Review } & \text { Indicating a } & \text { Indicting no } & \text { Indicating In- } \\ \text { Article } & \text { Positive Effect } & \text { Effect } & \text { conclusive Data }\end{array}$

Edwards,

Norton

Taylor,

Weise, \&

Dusseldorp, 1975

9

Thomas, 1978

Wilson, $1980 \quad 19$

19

3

4

Jamison,

Suppes,

\& Wells,

1974

8

5

2

Kulik,

Bangert,

\& Williams,

1983

39

9

Rappaport

\& Savard,

1980

10

-

2

Totals

137

17

8

* Includes studies that report some support but may not be statistically significant. 
TABLE II

THE EFFECT OF CAI ON ACHIEVEMENT WHEN USED AS A SUBSTITUTE FOR TRADITIONAL INSTRUCTION

\begin{tabular}{llll}
\hline & *Studies cited & Studies cited & studies cited \\
Review & $\begin{array}{l}\text { Indicating a } \\
\text { Article }\end{array}$ & $\begin{array}{l}\text { Indicting no } \\
\text { Positive Effect }\end{array}$ & $\begin{array}{l}\text { Indicating In- } \\
\text { conclusive Data }\end{array}$ \\
\hline
\end{tabular}

Edwards, Norton

Taylor, Weise, \& Dusseldorp,

1975

9

$-$

11

Jamison,

Suppes, \&

Wells, 1974

1

10

11

Totals

$-$

* Includes studies that report some support but may not be statistically significant.

The 32 studies reviewed by Edwards et al. (1975) were carried out in primary, secondary or college classes. Effectiveness was measured by student achievement as a result of CAI as compared with achievement resulting from other methods of instruction. They found that normal instruction supplemented by CAI was more effective than normal instruction alone. In some cases the gains were impressive. Third grade math students gained more than two grade levels in computational ability in studies done in California and Mississippi. Reading ability also increased at a greater rate when supplemented with computer-assisted 
instruction. In one study, students who received supplementary CAI instruction in reading scored an average of 0.6 grade levels higher on standardized tests than students who received normal classroom instruction only. Another study reviewed reported that a group of fourth and fifth graders made an average of seven months growth in reading skills during the four months that their normal instruction was supplemented with CAI. When computer-assisted instruction was substituted for traditional instruction in whole or in part, the authors found that in nine studies the CAI students achieved more than the non-CAI students, while in eight little or no difference was detected. Three studies reviewed showed mixed results.

When the authors looked at the effectiveness of different modes of CAI, they could not conclude that any one mode was consistently more effective in the area of achievement than any other. However, each mode of CAI was shown to be more effective than traditional instruction in some studies but not more effective in others. When CAI was compared with other non-traditional methods of instruction it was found to be equaliy effective.

In one study reviewed by Thomas (1978), normal achievement growth was obtained, but the growth was $50 \%$ better than that obtained prior to the introduction of CAI. Many other studies reviewed reported positive results obtained via CAI. These included significant score changes 
on portions of national achievement tests, increases in basic skills and a reversal in one school district of a sixteen year decline in standard achievement test scores. The studies reviewed which attempted to evaluate the effectiveness of CAI overwhelmingly supported CAI as a viable instructional alternative. At the secondary level, the studies showed higher achievement scores whether measured by teacher-made tests, gain scores on local or standardized tests or on predicted vs. actual scores using regression analysis methods. Several studies done at the post-secondary level were cited which indicate equal or favorable effectiveness of computer-based approaches regardless of the mode of CAI employed.

Kulik et al. (1983) did a meta-analysis of 51 objective, comparative studies of computer-assisted instruction at the elementary and secondary level. The studies covered the five areas of drill and practice, tutoring, computermanaged teaching, simulation and programing of the computer to solve problems. In more than $80 \%$ of the 48 studies that described the effects of CAI on achievement test scores, students from the CAI classes received at least slightly better scores than did the students from the control classes. In more than $90 \%$ of the 25 studies reporting a statistically significant difference in results from the two teaching approaches, students from CAI classes received the higher scores. The average effect of CAI in the 48 studies 
was to raise student test scores by .32 standard deviations, or from the 50th to the 63rd percentile. Analyses were carried out to determine whether different types of studies were producing different results. These analyses did not disclose any strong relationships between study features and achievement test results. Effects on achievement scores tended to be somewhat higher in studies of CAI published during the last five years and were greater in studies of shorter duration. Kulik et al. noted that their findings were consistent for the most part with findings of earlier reviews. No research was identified that looked at interactions between the use of CAI, learning styles and achievement.

\section{The Effect of CAI on students' Attitudes}

An important aspect of the use of CAI in education is student attitudes about its use. Five review articles were identified which summarized research on CAI and student attitudes. Forty-two of these studies indicated that students had a positive attitude toward CAI, four showed no effect, and twenty-eight were inconclusive. The size of the effect on student attitudes was small.

In eight of the ten studies reviewed by kulik et al. (1983) that reported results on students' attitudes toward the subject matter being taught, attitudes were more 
positive in the classrooms using CAI. However, the average size of the effect was only at .12 standard deviation.

Students from CAI classes gave more favorable ratings but none of the differences between the classes were statistically significant. In general, CAI had a positive effect on student attitudes toward subject matter in a majority of the studies (see Table III).

TABLE III

THE EFFECT OF CAI ON STUDENT ATTITUDES TOWARD SUBJECT MATTER

\begin{tabular}{|c|c|c|c|}
\hline $\begin{array}{l}\text { Review } \\
\text { Article }\end{array}$ & $\begin{array}{l}\text { *Studies Cited } \\
\text { Indicating a } \\
\text { Positive Effect }\end{array}$ & $\begin{array}{l}\text { Studies cited } \\
\text { Indicting a } \\
\text { Negative Effect }\end{array}$ & $\begin{array}{l}\text { Studies cited } \\
\text { Indicating In- } \\
\text { conclusive Data }\end{array}$ \\
\hline $\begin{array}{l}\text { Kulik, } \\
\text { Bangert, \& } \\
\text { Williams, } \\
1983\end{array}$ & 8 & 2 & - \\
\hline Thomas, 1978 & 10 & 1 & 7 \\
\hline $\begin{array}{l}\text { Wilson, } 1980 \\
\text { Jamison, } \\
\text { Suppes, } \\
\text { \& Wells, } \\
1974\end{array}$ & 21 & - & 21 \\
\hline $\begin{array}{l}\text { Rappaport } \\
\text { \& Savard, } \\
1980\end{array}$ & 2 & - & $\ldots$ \\
\hline Totals & 42 & 4 & 28 \\
\hline
\end{tabular}

* Includes studies that report some support but may not be statistically significant. 
The Effect of CAI on Time spent

Five review articles were identified which looked at the effect of CAI compared to traditional methods on the amount of time it takes to complete course material. All of the studies reviewed found that the use of CAI resulted in a saving of student time (see Table IV). Edwards et al. (1975) noted that in the nine studies identified that looked at the time factor, it took less time for students to learn with CAI than other methods even though CAI did not result in greater achievement in six of the nine studies. Rappaport and Savard (1980) found that CAI resulted in students completing the same material in less time or more material in the same time. The studies reviewed clearly showed that students receiving CAI completed the same materials in less time than traditionally instructed students.

\section{The Effect of CAI on Retention}

The effect of CAI on retention was discussed in five of the review articles. Sixteen studies showed a positive effect, three showed no effect and twenty were inconclusive (see Table V).

Edwards et al. (1975) found three studies that looked at student retention over time compared with students who were taught traditionally. one study done at the college level showed retention to be equal, while the other two 
studies (one in grade six and one in high school) showed that students who learned through traditional methods retained more of what they had learned than students who learned through CAI.

TABLE IV

THE EFFECT OF CAI ON THE AMOUNT OF TIME IT TAKES TO COMPLETE COURSE MATERIAL COMPARED TO. TRADITIONAL INSTRUCTION

\begin{tabular}{|c|c|c|c|}
\hline $\begin{array}{l}\text { Review } \\
\text { Article }\end{array}$ & $\begin{array}{l}\text { * Studies cited } \\
\text { Indicating a } \\
\text { Positive } \\
\text { Effect }\end{array}$ & $\begin{array}{l}\text { Studies Cited } \\
\text { Indicting a } \\
\text { Negative } \\
\text { Effect }\end{array}$ & $\begin{array}{l}\text { Studies Cited } \\
\text { Indicating } \\
\text { Inconclusive } \\
\text { Data }\end{array}$ \\
\hline $\begin{array}{l}\text { Edwards, } \\
\text { Norton } \\
\text { Taylor, } \\
\text { Weise, \& } \\
\text { Dusseldorp, } \\
1975\end{array}$ & 9 & - & - \\
\hline Thomas, 1978 & 10 & - & - \\
\hline Wilson, 1980 & 2 & - & - \\
\hline $\begin{array}{l}\text { Kulik, } \\
\text { Bangert, } \\
\& \text { williams, } \\
1983\end{array}$ & 2 & - & - \\
\hline $\begin{array}{l}\text { Jamison, } \\
\text { Suppes, } \\
\& \text { Wells, } \\
1974\end{array}$ & 3 & - & - \\
\hline Totals & 26 & - & - \\
\hline
\end{tabular}

* Includes studies that report some support but may not be statistically significant. 
TABLE V

THE EFFECT OF CAI ON RETENTION OF COURSE MATERIAL LEARNED

\begin{tabular}{|c|c|c|c|}
\hline $\begin{array}{l}\text { Review } \\
\text { Article }\end{array}$ & $\begin{array}{l}\text { *Studies cited } \\
\text { Indicating a } \\
\text { Positive } \\
\text { Effect }\end{array}$ & $\begin{array}{l}\text { Studies cited } \\
\text { Indicting a } \\
\text { Negative } \\
\text { Effect }\end{array}$ & $\begin{array}{l}\text { Studies cited } \\
\text { Indicating } \\
\text { Inconclusive } \\
\text { Data }\end{array}$ \\
\hline $\begin{array}{l}\text { Edwards, } \\
\text { North, } \\
\text { Taylor, } \\
\text { Weise, \& } \\
\text { Dusseldorp, } \\
1975\end{array}$ & 9 & - & 9 \\
\hline Wilson, 1980 & 2 & 2 & - \\
\hline Thomas, 1979 & - & - & 10 \\
\hline $\begin{array}{l}\text { Kulik, } \\
\text { Bangert, } \\
\& \text { williams, } \\
1983\end{array}$ & 5 & 1 & - \\
\hline $\begin{array}{l}\text { Rappaport } \\
\text { \& Savard, } \\
1980\end{array}$ & - & - & 1 \\
\hline Totals & 16 & 3 & 20 \\
\hline
\end{tabular}

* Includes studies that report some support but may not be statistically significant.

Five of the studies reviewed by Kulik et al. (1983) looked at student retention for two to six months. In four of the studies, retention was higher for students in the CAI classes; however, this was not statistically significant. 
In the fifth study, retention was significantly higher in the traditional class.

Rappaport and savard (1980) reported that there was no consistent evidence that there was any difference in the retention rates of CAI and traditionally instructed students. They concluded that fears that students would forget CAI learned material more easily than traditionally learned materials appear to be unfounded although findings in this area were mixed or inconclusive.

Edwards et al. (1975) reviewed two studies that reported results according to ability level of students. Both studies reported that CAI drill and practice in arithmetic was relatively more effective for low ability students than for those of average or high ability. Since there were a limited number of studies available, results of this review could not be considered definitive.

\section{Summary}

The review articles discussed here all concluded that computer-assisted instruction, when combined with traditional instruction, leads to higher achievement than traditional instruction alone. There is less agreement about the effectiveness of CAI alone when compared to traditional instruction alone. Few authors recommend that computerassisted instruction replace traditional instructional methods. CAI had a positive effect on student attitudes 
toward subject matter in a majority of the studies. Another consistent finding was that students receiving CAI completed the same materials as traditionally instructed students in less time. There was no conclusive evidence that CAI students retained material over any longer or shorter period of time than students receiving traditional instruction.

Although some of the reviews of research included studies at the college level, the vast majority of studies involved students in the elementary or secondary grades.

\section{COMPUTER-ASSISTED INSTRUCTION AT THE} COLLEGE LEVEL

The educational advantages of computer-assisted instruction have been demonstrated by a number of studies at the elementary and secondary levels. The effects on instruction at higher levels of education have not been so easily identified. Jamison, Suppes and Wells (1974) reviewed several small scale studies of computer-assisted instruction at the college level and reported that computerassisted instruction is about as effective as traditional instruction when used as a replacement.

Kulik, Kulik and Cohen (1980) performed a metaanalysis to integrate findings from 59 independent studies of computer assisted college teaching. These studies were chosen from an initial pool of 500 titles. The criteria used for inclusion were that the studies had to: (a) take 
place in college classrooms, (b) report on quantitatively measured outcomes in both computer-based and conventional classes and (c) be free from crippling methodological flaws. In addition, guidelines were established to ensure that each comparison was counted only once in the analysis.

The studies described in the meta-analysis included four major types of computer application: tutoring, computer-managed teaching, simulation and programming the computer to solve problems. All studies either looked at the computer as a substitute for conventional teaching (replacing lectures, recitation sessions, etc.), or as a supplement to regular instruction providing an additional resource for students.

The authors identified five major outcomes from their review: the effect of computer-assisted instruction on achievement as measured on a unit or final examination; the effect of CAI on the correlation between student aptitude and achievement in college courses; the effect of CAI on course achievement; the effects of CAI on instruction and the direction and significance of differences in outcomes of computer-assisted and conventional teaching.

\section{schievement}

Fifty-four of the 59 studies reviewed looked at examination performance of students in conventional classes and those using CAI. In 37 of these, examination 
performance was superior for CAI compared to conventional classes. Seventeen studies favored conventional instruction. Statistical analysis showed that a typical student in a CAI class was performing at the 60th percentile on examinations; whereas, the typical control student performed at the 50th percentile. Nearly one-quarter of the studies reported a medium or large effect in favor of CAI, nearly three-quarters found small or trivial effects and less than five percent reported moderate or large effects favoring conventional instruction.

\section{Aptitude/Achievement Correlation}

Seven studies reviewed reported aptitude/achievement correlations separately for CAI and conventional classes. In three of the studies, the correlation between aptitude and achievement was higher in the CAI section. For the other four studies, the correlation was higher in the conventional classes. The authors concluded that CAI has at best a small effect on the correlation between aptitude and achievement in college courses.

\section{Course completion}

Thirteen of the studies in the review examined the effect of CAI on course completion. The difference in withdrawal rates was statistically significant in only three studies. In one of these, withdrawal was significantly 
higher in the CAI class; in two cases it was significantly higher in the conventional class.

\section{student Attitudes}

Results from eleven studies included quantitative comparisons of student attitudes toward instruction in computer-assisted and conventional classes. Ratings of CAI classes were higher than in conventional classes in eight of the studies, and conventional ratings were higher in the remaining three studies. Computer-based teaching also had a small effect on student attitudes toward the subject matter in these courses. In general, however, the authors pointed out that the effects of CAI on subject matter attitudes were small.

\section{Instructional Time}

Eight of the studies in this review looked at the amount of time spent in the instruction of students in CAI and conventional classes. In all of the studies, the computer-assisted instruction demonstrated a saving in instructional time. In all of the cases in which statistical tests were performed, the differences in instructional time between CAI and conventional classes were statistically significant. The authors note that there appears to be little doubt that students can be taught with computers in less time than with conventional methods of college teaching. 
Conclusions

The authors of this meta-analysis conclude that the computer has made a small but significant contribution to student learning in higher education. Typjcally, computerassisted instruction raised examination scores by about eight percentage points or about one-quarter standard deviation. However, the most dramatic finding reported was related to instructional time. In every study in which computer-assisted instruction substituted for conventional teaching, CAI students took only two-thirds of the time to learn the content than they did when conventional teaching methods were used. overall, the authors point out that the accomplishments of CAI at the college level are modest compared to the often impressive results seen for computerassisted instruction in the elementary schools. In general, there was little relationship between design features of experiments and experimental outcomes. In addition, neither the nature of publication (published vs. unpublished studies) or study year were significantly related to the study outcome.

The only variable that predicted study outcome in this meta-analysis was the use of a design that controlled for instructor effects. In studies in which different teachers taught computer-assisted and conventional sections of a course, examination differences were more clear-cut and favored computer-assisted teaching. In studies in which a 
single teacher taught both experimental and control classes, differences were less pronounced.

The authors point out that the picture drawn from this meta-analysis is one of the past not the future. They emphasize that the developments in computer technology are occurring so rapidly that no one can predict with confidence what the future will bring in computer-assisted college teaching.

\section{THE USE OF COMPUTER-ASSISTED INSTRUCTION} IN SCHOOLS OF NURSING

There are very few studies published in the literature about the effectiveness of CAI in teaching nursing students. All of the early studies that identify the computer system used report using PLATO. There are a few formal reports of the use of microcomputers for CAI. The one informal report about microcomputers describes the effective use of simulations to evaluate students' knowledge about clinical nursing.

In 1966, Bitzer described a project using the PLATO system in which a situation was developed that was almost completely student-directed. Students controlled the rate and direction of their learning using a simulation titled, "Care of the patient with a myocardial infarction." Results of the study showed that students in the experimental group learned as well or better than those in the control group. 
In addition, the more active a student had been in the learning process, the more that was learned. One student who had a record of poor classroom performance became a high achiever when using the computer lesson. All of the students except one stated that they felt this was an effective way of presenting the lesson material. The reasons given included comments about the opportunity for active participation in the learning process, immediate feedback about the correctness of their answers, and finding the answers themselves. Most of the students also stated that they liked the idea of being able to experiment with a patient situation and finding out what the consequences of their actions were without caring for an actual patient.

This initial study led Bitzer and Bitzer (1973) to adapt a maternity nursing course for use on PLATO. Material usually presented in the classroom was adapted to the computer. One class of students was divided into two groups matched according to ability. One group had the course on PLATO and the other had it in the conventional classroom manner. The two groups had one common two hour clinical conference per week. Post-test scores indicated a significant gain by all students, and a comparison of final examination grades did not indicate a significant difference between the two groups. The maximum time spent by a PLATO student was 50 hours compared with 84 hours by a control group student. In this study, the PLATO students learned 
the same amount of material in from one-third to one-half the time required in the classroom. While there was no reduction in student performance by the PLATO students, neither was there better achievement. When asked to evaluate the course, over $50 \%$ of students rated PLATO as the "best," "easiest" and "most preferred" medium over lecture, textbook or movie, while from 0 to $15 \%$ rated PLATO as "worst" or "hardest" to learn from. The authors noted that in an initial study carried out prior to the one reported, there was a highly significant increase in learning and long-term retention for an anatomy lesson taught by PLATO as opposed to a lecture presentation. They point out that this gain could have been attributed to either the superiority of the inquiry presentation and/or an enhanced distinctiveness of the material due to the novel method of presentation. The reported investigations using CAI in nursing and medical education led Hoffer, Mathewson, Loughrey and Barnett (1975) to use a computerized teaching program on cardiopulmonary resuscitation (CPR) in continuing education. Registered nurses were divided into control and experimental groups; a pretest/post-test design was used. The experimental group which used the CPR computer program showed a significant increase in their post-test scores while nurses in the control group did not. The authors suggested that the use of CAI in nursing education be expanded. 
In another funded study, Kirchoff and Holzemer (1979) examined the relationship among students' iearning preference styles, attitudes, and performance on a CAI program using the PLATO system. The investigators found that all students learned the required material. Those students who scored high on an Active Experimentation (doing) scale also had high scores on learning. Since there was no control group in this study, there was no way to determine if the computer-assisted instruction used was a better teaching technique than the formerly used written assignments. Faculty time was saved because they did not have to correct written assignments. In addition, student/faculty conference time that was previously used to discuss written assignments was available for other uses. students received immediate feedback for their work and spent less time completing the assignments. The most intriguing result of this study was the fact that students' perceptions of the degree of dullness of learning on PLATO was inversely related to learning. That is, students who perceived learning on the computer system as less dull learned more than students who perceived the learning as dull.

In the 1970s, Huckabay, Loucine, Anderson, Holm and Lee (1979) studied the effect of CAI vs. lecture/discussion on nurse practitioner students studying the clinical management of the hypertensive patient. Content on the subject was presented to both the control and experimental groups in 
the traditional manner. The control group also studied the content by means of the computer. This consisted of 15 case studies about patients with hypertension which enabled the students, using a simulation to interview the patients, get a physical examination report and medical and nursing history, make a diagnosis and prescribe an intervention. The students received immediate feedback on their response to determine if they were correct. Branching was used if responses were incorrect to allow the students to correct their errors. Results showed that there were no significant differences between the control and experimental groups in cognitive learning, transfer of learning or affective behaviors. However, post-test scores on both types of learning showed that the experimental group had a significantly greater ability to transfer knowledge learned to patient situations.

Boettcher, Alderson and Saccucci (1981) carried out a study to determine if computer-assisted instruction would yield statistically significant differences in learning outcomes from printed programmed instruction in the cognitive categories of knowledge and application. Lessons in psychopharmacological nursing were developed which presented the same learning material for both teaching modalities. A pretest/post-test control group design was used. Initial student learning and retention of learning in the cognitive categories of application and retention of learning were 
studied. The results of the investigation revealed no significant differences in post-test scores related to either knowledge or application. Both groups demonstrated substantial initial learning in both cognitive categories followed by a moderate but significant drop in performance on the delayed post-test. Both groups made equally significant gains in the amount and application learned. This finding suggests that CAI can be as effective as a more traditional instructional modality in teaching both factual content and application of learned material. When the students were asked to report positive or negative attitudes to their assigned mode of study, those in the CAI group were significantly more favorable than those using programmed instruction. The authors suggest that this finding be interpreted with caution since the students' previous experience with CAI had been limited and the use of the computer may have been an appealing novelty to them. The effectiveness of CAI on achievement and attitude variables was studied by Conklin (1983), using a computerassisted instruction module about surgical nursing. Two comparison groups were used. Experimental and traditional groups received classroom instruction and a reference reading list. The experimental group was also instructed to complete eight CAI units. The control group did not receive any instruction in surgical nursing. The purpose of this group was to control for learning resulting from clues 
gained from the pretest and any incidental learning that my have occurred in the interval between the pre and posttests. The CAI group was found to achieve significantly greater gains in learning than the other two groups. The positive attitude toward CAI increased in all groups; however, the CAI group showed a significant improvement in attitude toward computer-assisted instruction. These results were seen as supporting the use of CAI for teaching surgical nursing topics. This study supports the value of CAI as compared to more traditional teaching methodologies.

A few studies have been done to compare the effects of CAI and lecture upon retention. Bitzer and Bitzer (1973) comparing the pretest to post-test scores of five CAI lessons concluded that CAI results in substantial learning and retention. Two retention studies which used comparison groups defined retention as knowledge at eight weeks or less (Boettcher et al., 1981; Day \& Payne, 1984). No significant difference in retention was found in either study. Gaston (1988) also studied retention using a two group post-test design with a second post-test eight months later. This researcher found that there was no significant difference in retention of knowledge between CAI and lecture groups.

Day and Payne (1984) compared student learning under CAI and the traditional lecture method. The data analysis of the results of this quasi-experimental study revealed that CAI is as effective as the traditional lecture method 
in bringing about learning as measured by exam scores. The results of a semantic differential attitude scale showed that students in this study did not rate CAI as a positive instructional method. CAI was rated as more useless, inappropriate, frustrating, slow, disturbing, exhausting, inconvenient, discouraging and ineffective. In general, they did not rate CAI as an enjoyable or valuable experience. These results are in conflict with findings reported in the literature by other researchers. Day and Payne have suggested several reasons for students' negative attitudes: lack of student control, lack of feedback on rationale for incorrect answers, lack of interaction between student and faculty and faculty and student orientation to CAI.

Gaston (1988) used a similar seven-point semantic differential scale in her study of knowledge, retention and attitude effects of CAI. In her study, student attitudes toward CAI were positive. Additional findings in her study were that there was no significant different in knowledge between the CAI and lecture groups. In addition, there was no significant difference between the two groups in retention of knowledge.

A different evaluation of computer-assisted instruction was used by Schleutermann, Holzemer and Farrand (1983). Two formats of delivering clinical simulations for nurse practitioners were evaluated. The formats included paperand-pencil, latent-image format and computer-assisted 
instruction. Twelve students in a graduate family nurse practitioner curriculum were the subjects. The authors found no preference for either type of format, nor any differences in student performance when the two formats were compared. Students' reactions to both types of simulations as a learning tool were very positive. They perceived the PLATO format as providing more immediate feedback and being more time efficient. On the other hand, the latent-image format was considered to be more convenient to complete since it could be done at a location and time of the students' choice.

Valish and Boyd (1975) used a post-test only design to study the role of computer-assisted instruction in the continuing education of registered nurses. The purpose of this study was to determine whether CAI could be a source for verifying and augmenting clinical knowledge in nursing. The authors found that the computer program could verify knowledge but not augment it. They attributed these findings to the fact that registered nurses were not significantly different from one another in their clinical knowledge. They recommended that CAI be used for continuing education by developing programs based on the needs of the nurses in the institution for which the program is being developed.

An informal report by Timpke and Janney (1981) was published in the nursing literature. The authors designed a 
CAI program to teach drug dosages. The program consisted of three diagnostic tests. The first was to review basic math skills necessary for the calculation of drug dosages, the second consisted of conversions from one system of measures to another, and the third was the calculation of drug dosages. The students had to achieve $100 \%$ competence in one test before going on to the next. This program was developed because of the need for teaching math remediation to students prior to allowing them to calculate drug doses and give patients medications. The authors found that the program saved them many hours that would have been spent counseling individual students. In addition, they found that student responses to the program were very positive. They liked being able to use the program privately and taking the tests as many times as necessary to get a perfect score. The program saved them the embarrassment of having an instructor know that they were deficient in basic skills in mathematics. It also saved them hours of trying to sift through a 200 page text to find what they needed to review. Among the student comments was the request that more programs be put on the computer. Before the computer program was used, 11 students out of 28 failed a final master examination in the calculation of drug dosages. The first semester in which the computer was fully implemented $100 \%$ of the students passed the final exam. 
The use of computer simulations in nursing education has not been confined to computer-assisted instruction programs developed exclusively for course work. In 1972, Sumida described the use of a computerized test for clinical decision making. The test consisted of clinical incidents which were programmed to permit students to decide how they would respond in a given situation. It was developed to evaluate the end-product achievement of graduating nursing students. The test results pointed to areas in which students might need guidance and supervision. Results also indicated content areas which nursing faculty needed to revise. This use of computer simulations was to evaluate achievement. The author suggested that the computer might be used to assist students and faculty in evaluating strengths and weaknesses in the clinical nursing courses. Olivieri and Sweeney (1980) described the use of computer simulations for the evaluation of nursing students. Life-like clinical situations were simulated for students to perform nursing assessments and make judgments about patient care based on those assessments. In the program used for evaluation, the students were not given a choice of objective responses with a computer reaction to their choice. Instead, they received answers to questions they posed and proceeded to the completion of a nursing assessment based on the data they collected. This was much like what students would do in a clinical setting. 
The purpose of the evaluation tool was to help faculty learn about the clinical expertise of their nursing students. The computer program provided an opportunity that could not be duplicated in an actual setting. The nursing process was applied by each student to the very same patient. This allowed the faculty an opportunity to do an indepth appraisal of each student and also provided for direct comparisons between students.

The authors of this article were not discussing the findings of a formal research study. Instead, they were describing how microcomputers can be used for the clinical evaluation of students' progress. This is one of the few articles in the journals that discusses the use of microcomputers for nursing education. Along with a description of how the microcomputers were used with students, the authors described the advantages of the system, discussed other uses for a microcomputer, and what is needed to develop a system. They point out that while the microcomputer cannot replace the actual clinical experience, it can extend and amplify those experiences and provide a means for the evaluation of students' skills by faculty members.

It is difficult to adequately assess the effectiveness of CAI in nursing education due to the variations in designs and paucity of published studies. The type of CAI used has varied among the modes of drill and practice, tutorial and simulations. Most of the investigations have looked at the 
instructional time required. Motivation and the ability to transfer knowledge have also been evaluated (see Table VI). The results of these investigations imply that CAI can be used effectively in a variety of programs in nursing education.

\section{TABLE VI}

COMPARISON OF NURSING STUDIES IN AREAS OF STUDENT ACHIEVEMENT, STUDENT ATTITUDES, INSTRUCTIONAL TIME AND OTHER FINDINGS

\begin{tabular}{|c|c|c|c|c|}
\hline study & $\begin{array}{l}\text { Student } \\
\text { Achievement }\end{array}$ & $\begin{array}{l}\text { student } \\
\text { Attitude }\end{array}$ & $\begin{array}{l}\text { Instructional } \\
\text { Time }\end{array}$ & other \\
\hline $\begin{array}{l}\text { Bitzer, } \\
1966\end{array}$ & $\begin{array}{l}\text { CAI students } \\
\text { learned as } \\
\text { well or } \\
\text { better }\end{array}$ & $\begin{array}{l}\text { Positive } \\
\text { for CAI; } \\
\text { liked } \\
\text { simulation }\end{array}$ & --- & -- \\
\hline $\begin{array}{l}\text { Bitzer \& } \\
\text { Bitzer, } \\
1793\end{array}$ & $\begin{array}{l}\text { No dif. } \\
\text { between } \\
2 \text { groups } \\
\text { (cAI and } \\
\text { traditional) }\end{array}$ & -- & $\begin{array}{l}\text { CAI group } \\
\text { learned same } \\
\text { amount in } \\
\text { less time }\end{array}$ & --- \\
\hline $\begin{array}{l}\text { Valish } \\
\& \text { Boyd, } \\
1975\end{array}$ & --- & -- & -- & $\begin{array}{l}\text { CAI helps } \\
\text { verify } \\
\text { knowledge } \\
\text { but no } \\
\text { sig. dif. } \\
\text { from } \\
\text { trad. } \\
\text { approach }\end{array}$ \\
\hline $\begin{array}{l}\text { Hoffer, } \\
\text { Mathewson, } \\
\text { Loughrey, } \\
\& \text { Barnett, } \\
1975\end{array}$ & $\begin{array}{l}\text { sig. inc. } \\
\text { in post-test } \\
\text { scores in CAI } \\
\text { groups vs. } \\
\text { traditional }\end{array}$ & -- & --- & -- \\
\hline
\end{tabular}


TABLE VI

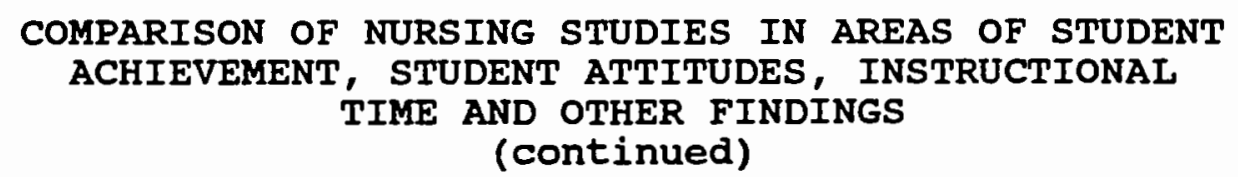

\begin{tabular}{|c|c|c|c|c|}
\hline study & $\begin{array}{l}\text { student } \\
\text { Achievement }\end{array}$ & $\begin{array}{l}\text { student } \\
\text { Attitude }\end{array}$ & $\begin{array}{l}\text { Instructional } \\
\text { Time }\end{array}$ & other \\
\hline $\begin{array}{l}\text { Kirchoff \& } \\
\text { Holzemer, } \\
1979\end{array}$ & -- & --- & $\begin{array}{l}\text { Less faculty } \\
\text { time needed } \\
\text { for instruc- } \\
\text { tion }\end{array}$ & $\begin{array}{l}\text { Motiva- } \\
\text { tion } \\
\text { predicted } \\
\text { learning }\end{array}$ \\
\hline $\begin{array}{l}\text { Huckaby, } \\
\text { Loucine, } \\
\text { Anderson, } \\
\text { Holm, \& } \\
\text { Lee, } 1979\end{array}$ & $\begin{array}{l}\text { No dif. } \\
\text { between } 2 \\
\text { groups (CAI } \\
\text { and tradi- } \\
\text { tional }\end{array}$ & -- & --- & $\begin{array}{l}\text { Post-test } \\
\text { scores } \\
\text { showed } \\
\text { cAI group } \\
\text { had sig. } \\
\text { greater } \\
\text { ability } \\
\text { to } \\
\text { transfer } \\
\text { knowledge } \\
\text { to } \\
\text { patient } \\
\text { situa- } \\
\text { tions }\end{array}$ \\
\hline $\begin{array}{l}\text { Timpke \& } \\
\text { Janney, } \\
1981\end{array}$ & -- & $\begin{array}{l}\text { students } \\
\text { liked CAI } \\
\text { better than } \\
\text { traditional } \\
\text { methods }\end{array}$ & $\begin{array}{l}\text { students } \\
\text { thought CAI } \\
\text { less time } \\
\text { consuming }\end{array}$ & --- \\
\hline $\begin{array}{l}\text { Boetcher, } \\
\text { Alderson, } \\
\text { Saccucci, } \\
1981\end{array}$ & $\begin{array}{l}\text { No dif. } \\
\text { \& between } 2 \\
\text { groups (CAI } \\
\text { and pro- } \\
\text { grammed } \\
\text { instruction) }\end{array}$ & $\begin{array}{l}\text { Signifi- } \\
\text { cantly more } \\
\text { favorable } \\
\text { toward CAI }\end{array}$ & -- & -- \\
\hline $\begin{array}{l}\text { Conklin, } \\
1983\end{array}$ & $\begin{array}{l}\text { sig. inc. } \\
\text { in achieve- } \\
\text { ment for } \\
\text { CAI vs. } \\
\text { traditional } \\
\text { method }\end{array}$ & $\begin{array}{l}\text { sig. inc. } \\
\text { in positive } \\
\text { attitude for } \\
\text { CAI group }\end{array}$ & $-\infty$ & -- \\
\hline
\end{tabular}


TABLE VI

COMPARISON OF NURSING STUDIES IN AREAS OF STUDENT ACHIEVEMENT, STUDENT ATTITUDES, INSTRUCTIONAL TIME AND OTHER FINDINGS (continued)

\begin{tabular}{|c|c|c|c|c|}
\hline study & $\begin{array}{l}\text { Student } \\
\text { Achievement }\end{array}$ & $\begin{array}{l}\text { student } \\
\text { Attitude }\end{array}$ & $\begin{array}{l}\text { Instructional } \\
\text { Time }\end{array}$ & other \\
\hline $\begin{array}{l}\text { Schleuter- } \\
\text { mann, } \\
\text { Holzemer, } \\
\text { Farrand, } \\
1983\end{array}$ & $\begin{array}{l}\text { No dif. } \\
\text { between CAI } \\
\text { \& and paper } \\
\text { \& pencil } \\
\text { format }\end{array}$ & $\begin{array}{l}\text { No prefer- } \\
\text { ence for } \\
\text { either type }\end{array}$ & -- & --- \\
\hline $\begin{array}{l}\text { Day \& } \\
\text { Payne, } \\
1984\end{array}$ & $\begin{array}{l}\text { No dif. } \\
\text { between } 2 \\
\text { groups } \\
\text { (CAI and } \\
\text { traditional }\end{array}$ & $\begin{array}{l}\text { More } \\
\text { negative } \\
\text { attitudes } \\
\text { CAI than } \\
\text { toward } \\
\text { traditional } \\
\text { method }\end{array}$ & --- & $\begin{array}{l}\text { No dif. } \\
\text { in re- } \\
\text { tention } \\
\text { between } \\
2 \text { groups }\end{array}$ \\
\hline $\begin{array}{l}\text { Gaston, } \\
1988\end{array}$ & $\begin{array}{l}\text { No dif. } \\
\text { between } 2 \\
\text { groups } \\
\text { (CAI and } \\
\text { traditional }\end{array}$ & $\begin{array}{l}\text { No dif. } \\
\text { between } \\
\text { groups; } \\
\text { both had } \\
\text { favorable } \\
\text { attitudes } \\
\text { toward CAI }\end{array}$ & -- & -- \\
\hline
\end{tabular}

\section{STATEMENT OF HYPOTHESES}

As stated previously, there is no reported research on the perceptual learning style characteristics of nursing students using the PEPS developed by Price, Dunn and Dunn (1982). In addition, there is little research to date that examines the relationship between student satisfaction with computer-assisted instruction and perceptual learning style 
characteristics. To determine if such a relationship exists, the following hypotheses were tested:

1. There will be a statistically significant negative correlation between auditory perceptual learning style and attitude toward computer-assisted instruction in the area of comfort.

2. There will be a statistically significant negative correlation between auditory perceptual learning style and attitude toward computer-assisted instruction in the area of creativity.

3. There will be a statistically significant negative correlation between auditory perceptual learning style and attitude toward computer-assisted instruction in the area of function.

4. There will be a statistically significant positive correlation between visual perceptual learning style and attitude toward computer-assisted instruction in the area of comfort.

5. There will be a statistically significant positive correlation between visual perceptual learning style and attitude toward computer-assisted instruction in the area of creativity.

6. There will be a statistically significant positive correlation between visual perceptual learning style and attitude toward computer-assisted instruction in the area of function. 
7. There will be a statistically significant positive correlation between tactile perceptual learning style and attitude toward computer-assisted instruction in the area of comfort.

8. There will be a statistically significant positive correlation between tactile perceptual learning style and attitude toward computer-assisted instruction in the area of creativity.

9. There will be a statistically significant positive correlation between tactile perceptual learning style and attitude toward computer-assisted instruction in the area of function. 


\section{CHAPTER III}

\section{METHODOLOGY}

This chapter includes a description of the setting, sample, proposed design of the study, development procedures, the instruments used for data collection, and the statistical methods for analyzing the data.

\section{SETTING}

This study was conducted at a baccalaureate school of nursing located on a health sciences university campus in the Pacific Northwest. At this school of nursing, one of the objectives for all students is to develop the knowledge needed to make clinical judgments and to develop the ability to recognize, analyze and solve nursing care problems. The methods most commonly used to achieve this objective are the use of classroom lecture and discussion and occasional videotapes. Factual knowledge is presented during lecture/ discussion sessions and is supplemented with required readings in textbooks and related journal articles. Computerassisted instruction has had minimal use in this school of nursing. 
SAMPLE

The sample for this study was sophomore nursing students. This group of students included sophomore students who entered the school of nursing on its two campuses Fall 1987, as well as a few students who were returning from a leave of absence. They were taking the course Nursing Science II, Patient Assessment (Nur 254). This course provides the theoretical basis for the physical, social and psychological assessment of the adult client. It serves as a foundation for developing and implementing a plan of nursing care which is prerequisite for all of the upper division courses in nursing. This researcher is responsible for teaching the classes about cardiovascular assessment which includes information about the cardiac exam. A lecture format is used along with in-class videotapes demonstrating the cardiac exam. In addition, students have assigned readings and are required to use the computer program, Cardiac Exam Bingo. This was the first time this computer program was used in this course.

\section{DESIGN}

A descriptive, correlational design was used for this research. This design was chosen because the purpose of this study was to identify and observe to what extent, if any, students' learning style perceptual preferences account 
for differences in student attitudes toward the use of computer-assisted instruction as a teaching method. Polit and Hungler (1983) note that the aim of a descriptive correlational study is to describe the relationship among variables rather than to infer cause and effect relationships.

At the beginning of the term, during class orientation, students were asked to complete the productivity Environmental preference survey (PEPS). The course syllabus was reviewed at that time and the required activities discussed. Students were told that use of the computer program, Cardiac Exam Bingo, was a course requirement. There were four copies of the program in the Instructional Media Department (IMD) and students were told when it was available for their use. Students were also asked to complete the attitude survey, Attitude Toward CAI Semantic Differential Tool. The importance of their cooperation in completing this tool was explained. Included in the explanation was the importance of this information to the plans for increasing the use of computer technology within the school of nursing specifically and within the university in general.

\section{INDEPENDENT VARIABLE}

The independent variable was students' learning style perceptual preferences. The students' learning style 
perceptual preferences were measured by the Productivity Environmental Preference Survey (PEPS) (Price, Dunn, \& Dunn, 1986). The method of instruction included the usual classroom lecture/discussion supplemented with the computer tutorial game Cardiac Exam Bingo developed by this investigator.

\section{DEPENDENT VARIABLE}

The dependent variable was the students' attitudes about the use of the computer program. The tool to be used was developed to measure student attitudes toward the use of computer-assisted instruction. It has three subscales: comfort, creativity and function.

The scores for these three attitudes were determined in the following way (Allen, 1986):

- Comfort: by adding scores on the four adjective pairs of :

$$
\begin{aligned}
& \text { pleasant - unpleasant } \\
& \text { comfortable - uncomfortable } \\
& \text { non-threatening - threatening } \\
& \text { easy to use - overpowering }
\end{aligned}
$$

- Creativity: by adding scores on the four adjective pairs of:

$$
\begin{aligned}
& \text { flexible - rigid } \\
& \text { stimulating - boring } \\
& \text { imaginative - unimaginative }
\end{aligned}
$$


personal - impersonal

- Function: by adding scores in the six adjective pairs of:

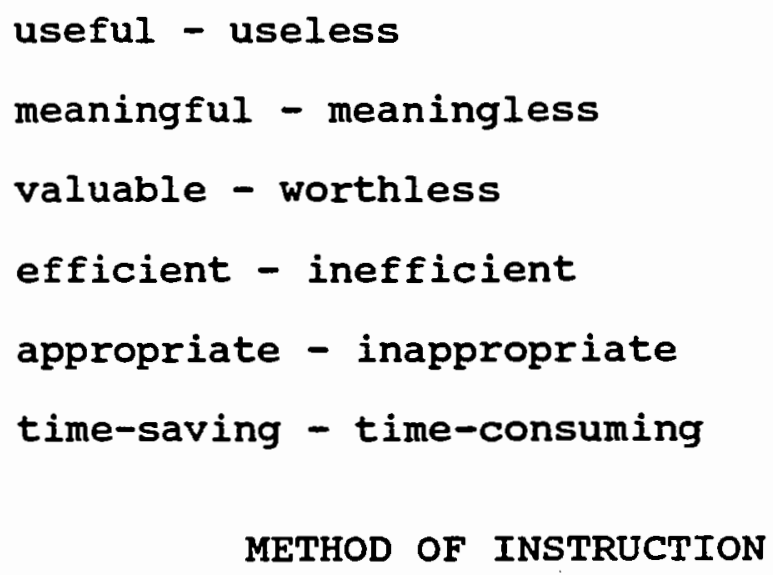

The method of instruction included the usual classroom lecture/discussion supplemented with the computer tutorial game, Cardiac Exam Bingo, developed by this investigator. Students were allowed to use the computer program for as long and as often as they wanted.

\section{DEVELOPMENT PROCEDURES}

Cardia Exam Bingo was developed to be used as a supplement to the classroom lecture about cardiac assessment. The design used was Edward's (1975) adaption of Dick's (1968) instructional design model (see Figure 1). A task analysis was the first step in the development of this computer program (see Figure 2). The target objective, to know facts about the cardiac examination, is one of the primary objectives for the class on cardiac assessment. The 
sub-objectives include information to be learned about the health history; inspection, palpation and auscultation of the heart; cardiovascular changes with aging; and laboratory tests. Understanding of the anatomy and physiology of the heart is the entry level behavior required by all students prior to enrollment in the course. The computer was chosen as the instructional medium to give students an opportunity to review the material at their own pace and introduce them to the use of a computerassisted instruction program as part of their educational experience. The bingo game format was chosen because it is familiar to most students and was considered a way for students to learn without causing frustration. It can also be used to give students positive feedback for correct responses and no penalty for incorrect answers. If students choose to have a debriefing at the end of the game, they are told the number of correct answers they chose on the first and second try and the number they missed. They are not given a percentage correct or incorrect. The bingo game format also provided an opportunity to design a tutorial program using a feedback loop (see Figure 3).

\section{INSTRUMENTS}

\section{Productivity Environment Preference Survey}

The three learning style inventories considered for this study were Hill's Cognitive style Mapping, Kolb's 


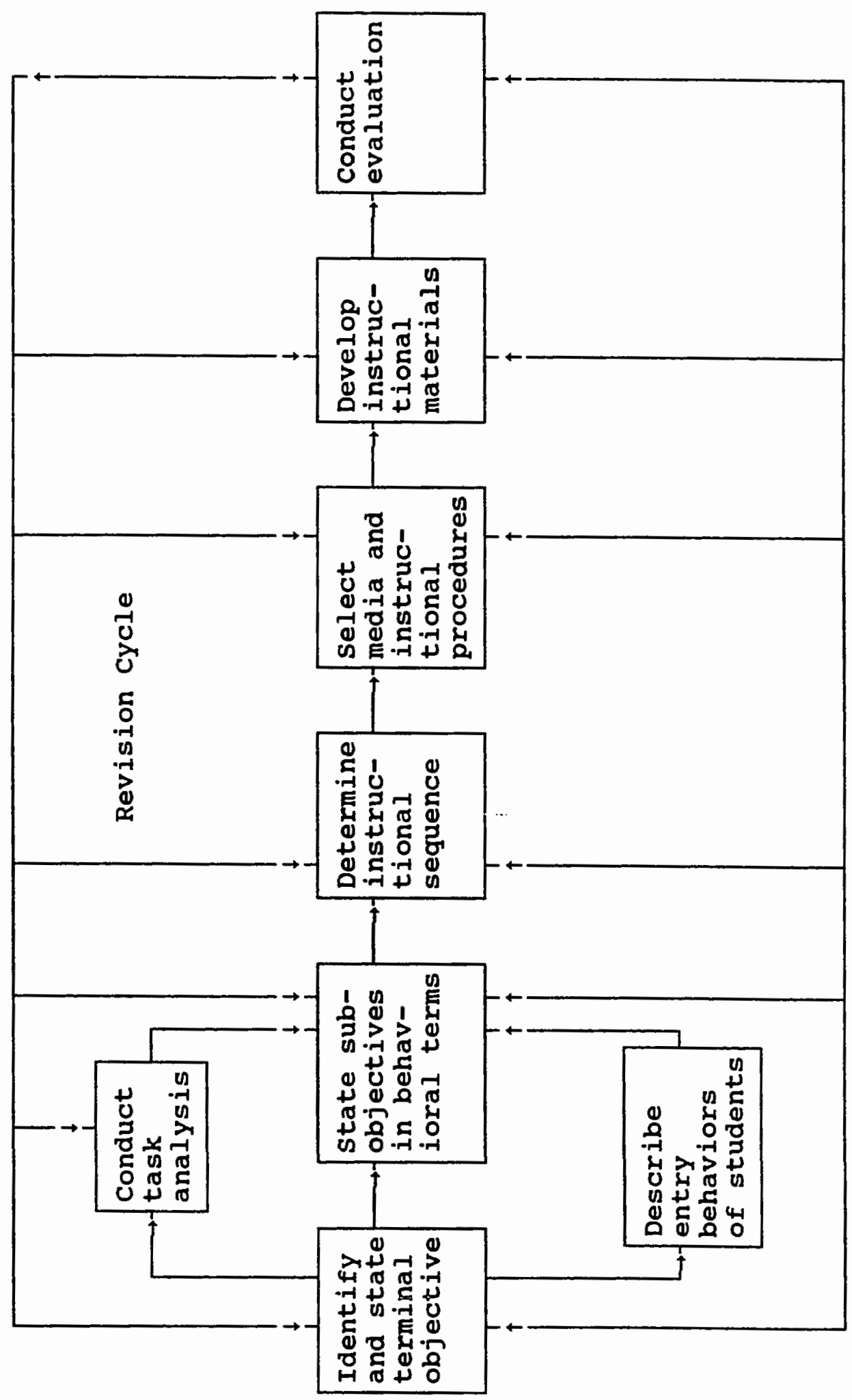

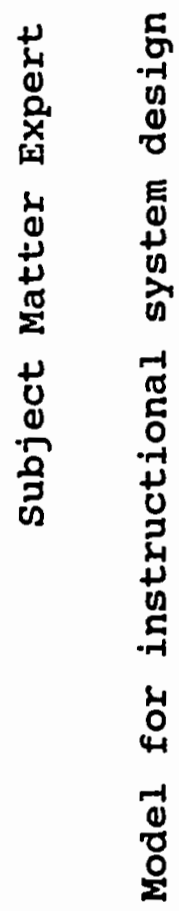

굴 


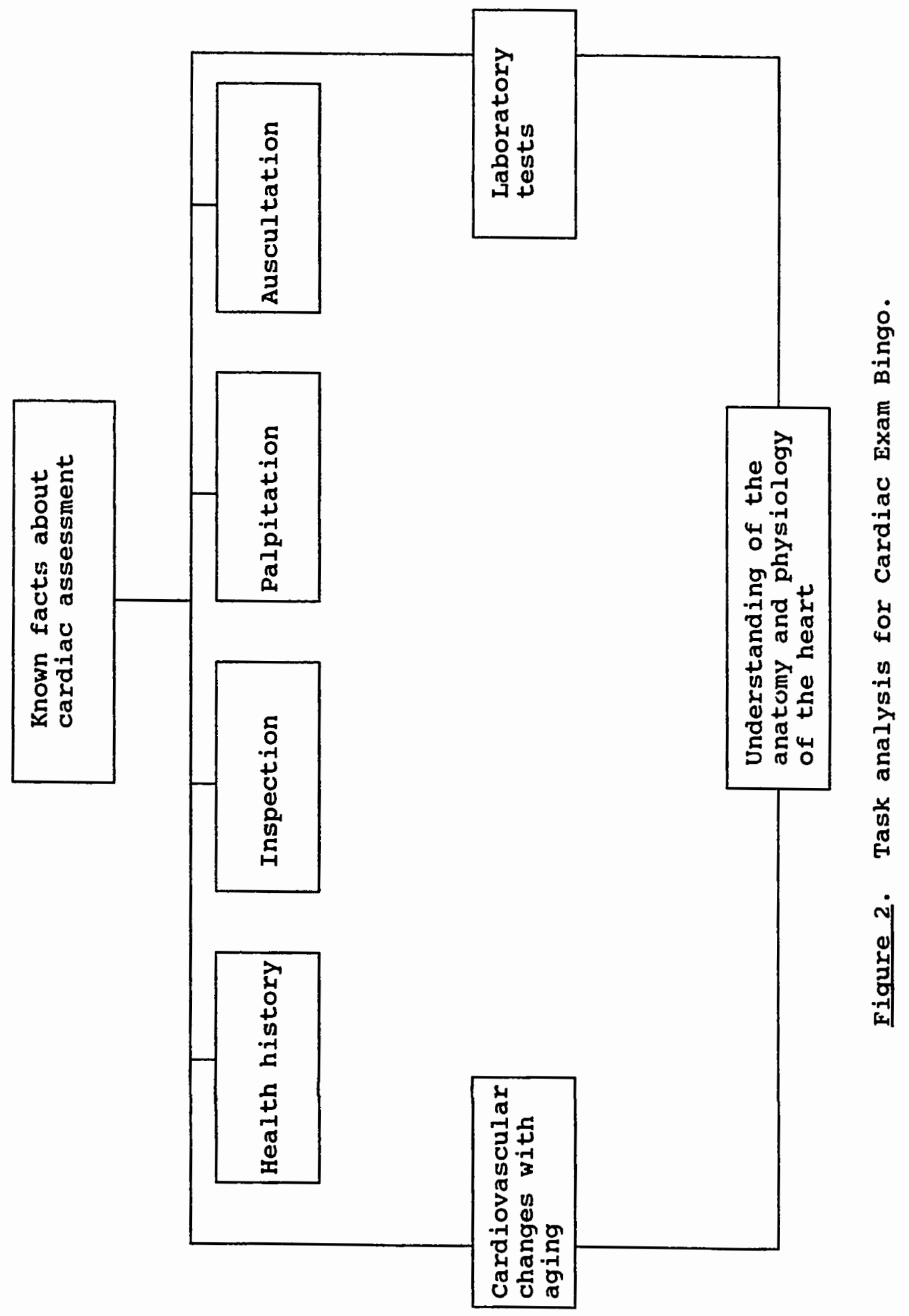




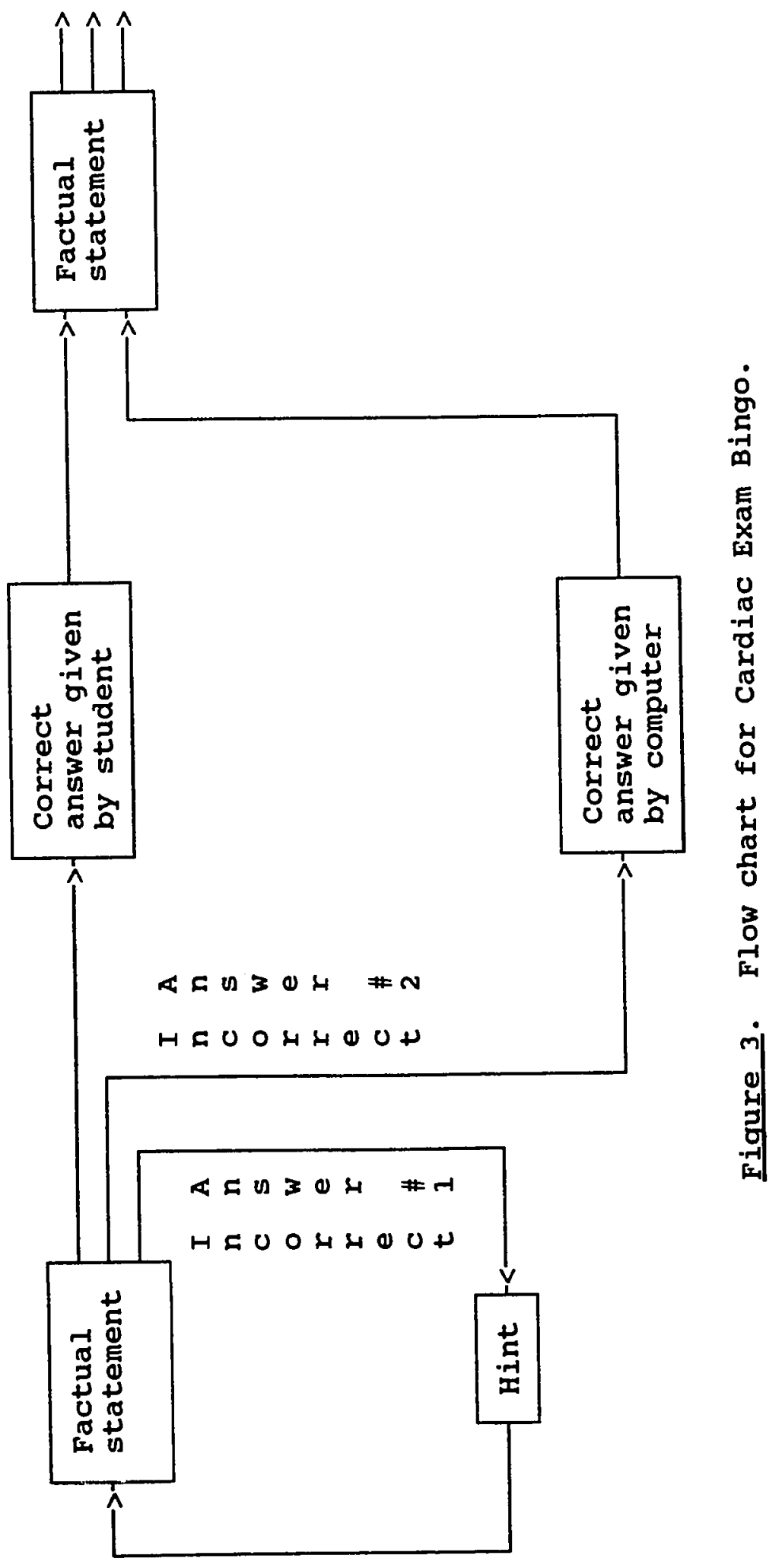


Learning style Inventory and Price, Dunn and Dunn's Productivity Environmental Preference Survey. Hill's instrument was not chosen because of the limited amount of controlled research used with it. The Kolb Learning style Inventory has been used to study the learning styles of nursing students; however, the results of that research suggest that nursing students have concrete learning styles. Thus when this instrument is used, there is little diversity among nursing students (Christiansen et al., 1979; Huck, 1981; Laschinger \& Boss, 1983; Marcinek, 1983; Seidman, 1983). For this investigation, the instrument selected to identify students' learning styles was the productivity Environmental Preference Survey (PEPS) (Price, Dunn, \& Dunn, 1986) (see Appendix A). This instrument was developed by identifying the research variables that appeared to describe the way adults preferred to learn or work. It was based on the Dunn, Dunn and Price Learning style Inventory (LSI) which is said to be the most widely used assessment instrument in elementary and secondary schools (Keefe, 1982). This instrument was designed for use in conjunction with several alternative approaches to individualized instruction such as the Contract Activity Packages, Learning Activity Packages, programmed learning and/or multisensory instructional packages (Learning style Inventory Research Report 1977). Computer-assisted instruction is also an alternative approach to individualizing instruction. 
The PEPS consists of 100 preference statements which diagnose an individual's (a) environmental, (b) emotional, (c) sociological and (d) physical characteristics within which are visual, auditory and tactile perceptual learning style characteristics. The answers to questions in each of those areas reveal a pattern of how individuals believe they learn. Developed through content and factor analysis, the PEPS uses dichotomous items and can be completed in approximately 30 to 40 minutes.

Each profile contains the individual's name or identification number, sex, date answer sheet was scored, group identification and standard score for each of the 20 areas. The standard score scale ranges from 20-80 with a mean of 40 and a standard deviation of 10. The standard score is calculated based on the scores of adults who have taken the PEPS. Individuals having a standard score of 60 or more strongly prefer that area as a factor when they study or work. Individuals having a standard score of 40 or less do not prefer that factor when they study or work. Individuals having scores that fall between 40 and 60 are varied with respect to how much that area is important to them. The following suggestions are made for adapting the working or learning environment in the areas of auditory, visual and tactile preferences. When an auditory preference standard score is 60 or more, tapes, videotapes, records, radio, : television and precise oral directions when giving 
assignments are suggested. A visual preference standard score of 60 or more suggests that resources that require reading and seeing be used. These include picture, filmstrips, computers, films, graphs, single concept loops, transparencies, diagrams, drawings, books and magazines. When a tactile preference standard score is 60 or more, manipulative and three dimensional materials such as resources that are touchable and moveable as well as readable should be used.

A study with 589 adults from several states and various academic and industrial settings who completed the PEPS revealed that $68 \%$ of the reliabilities were greater than .60. Auditory and visual preferences had higher reliability coefficients. They were .75 and .87 respectively. The reliability for tactile preference was a little less than the strongest elements at .56 .

The Learning Style Inventory (LSI) (Dunn, Dunn, \& Price, 1978), on which the PEPS was based, has been shown to have extensive predictive validity (DeBello,1985; Della Valle, 1984; Hodges, 1985; Krimsky, 1982; Kroon, 1985; Lynch, 1981; MacMurren, 1985; Murrain, 1983; Pizzo, 1981; Shea, 1983; Virostko, 1983; White, 1981). The PEPS, which has not been as widely used as the LSI, has also been shown to have predictive validity (Cafferty, 1980; Copenhaver, 1979; Domino, 1970; Farr, 1971). Cupke (1980) analyzed the effect on achievement of matching students with preferred 
learning styles. He reported that mixed results were obtained on the instruction, organization and direct experience learning environment preference scales for instructors and students. However, this study has been severely criticized in the Learning styles Network Newsletter (1982) for inadequacy of the design, the absence of a primary hypothetical focus and the shift from individuals to organizations in the analysis of the data.

The PEPS was chosen to be used in this investigation because it is the only tool that has been shown to have good reliability coefficients in the areas of auditory, visual and tactile perceptual preferences and appears to have predictive validity. Since there are no reports of the use of this instrument with nursing students in any published studies, the PEPS was given to a group of junior students at a health sciences university school of nursing to determine if there was any variability in the perceptual preferences of nursing students. It was important to have this information before proceeding with the study. If there was no variability, there would be no study.

Twenty-five nursing students completed the PEPS. There was variability in each perceptual preference area across the group; fifteen students had a standard score equal to or greater than 60 and four were at 40 or below (see Table VII). 
Table VIII shows the predominant learning style for each of the fifteen subjects that scored in the high range. Nine were high in auditory, three in visual and three in tactile. One of these subjects was high in both auditory and tactile preference.

TABLE VII

PERCEPTUAL PREFERENCES OF 25 NURSING STUDENTS IN THE AUDITORY, VISUAL AND TACTILE AREAS

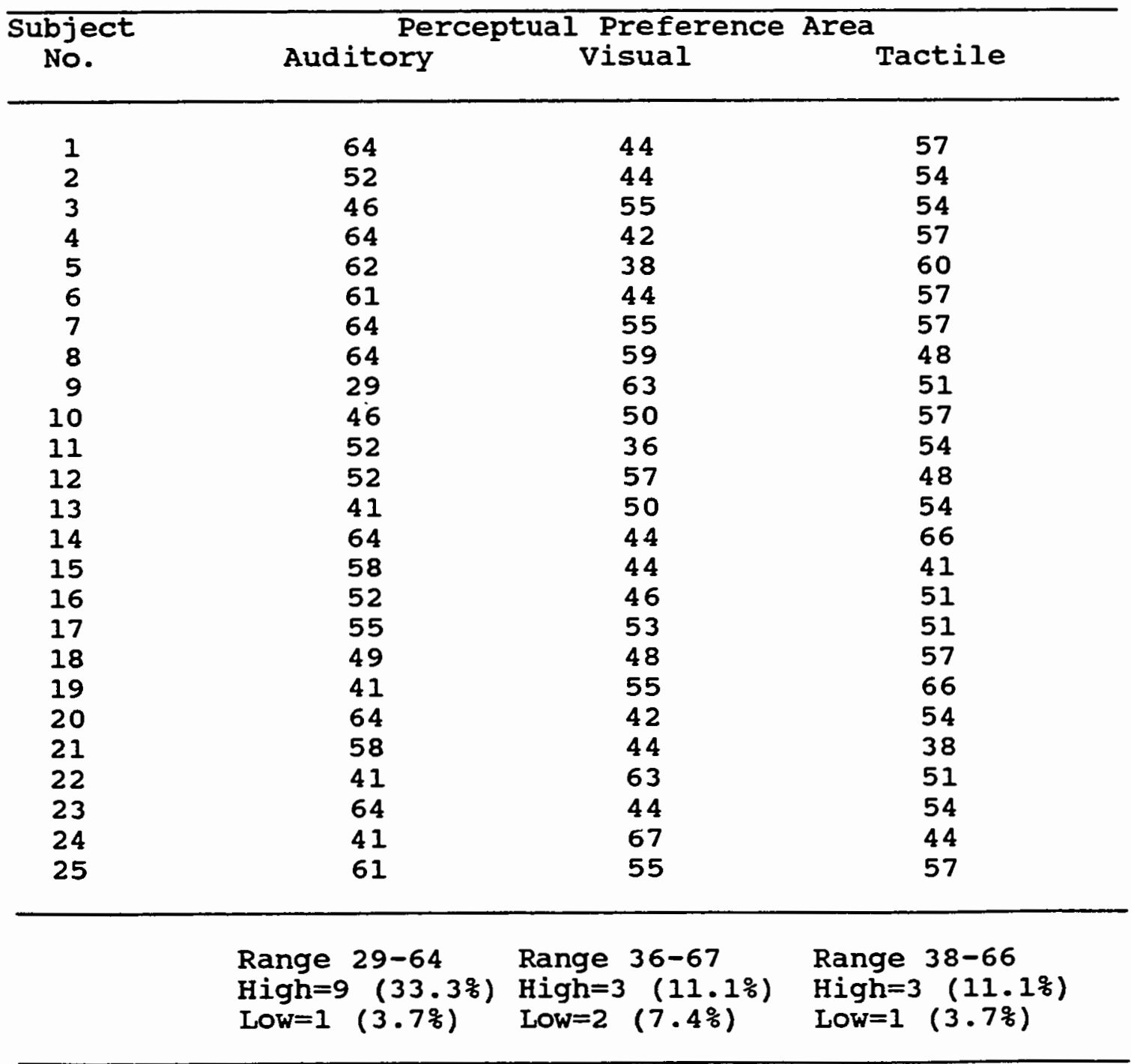


TABLE VIII

STUDENTS WITH A STANDARD SCORE EQUAL TO OR GREATER THAN 60 IN ONE OR MORE PERCEPTUAL PREFERENCE AREAS

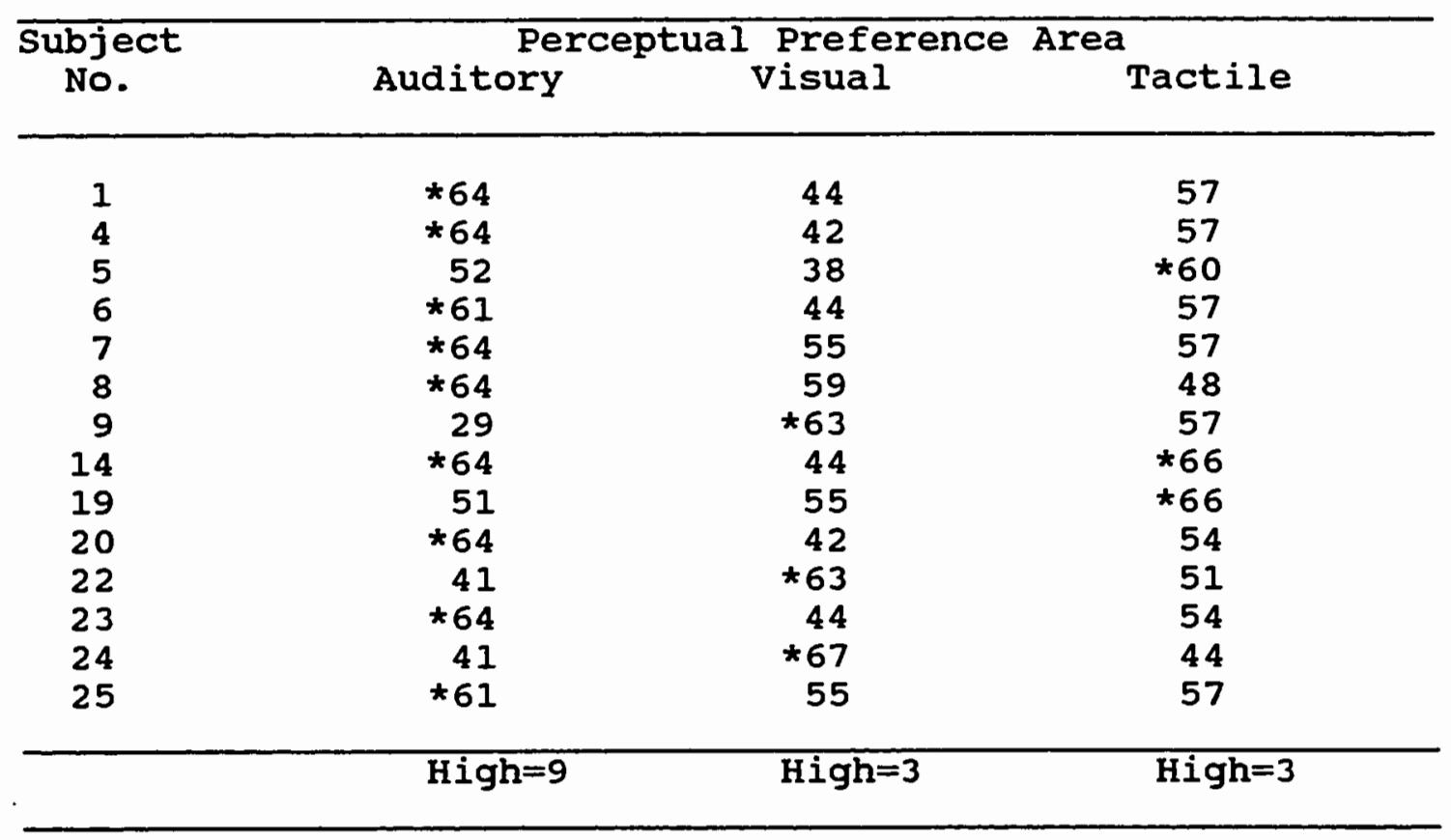

The four subjects that scored in the low range are shown on Table IX.

TABLE IX

STUDENTS WITH A STANDARD SCORE EQUAL TO OR LESS THAN 40 IN ONE OR MORE PERCEPTUAL PREFERENंCE AREAS

\begin{tabular}{rrrr}
\hline $\begin{array}{c}\text { Subject } \\
\text { No. }\end{array}$ & Auditory & Perceptual & Preference Area \\
Visual & Tactile \\
\hline 5 & 52 & $\star 38$ & 60 \\
9 & $\star 29$ & 63 & 51 \\
11 & 52 & $\star 36$ & 54 \\
21 & 58 & 44 & $\star 38$ \\
\hline & Low 1 & Low $=2$ & Low $=1$ \\
\hline
\end{tabular}


Table $\mathrm{X}$ shows the students whose perceptual preference areas were between 0.5 and 1.0 standard deviation above the mean. In this group, three students had a tendency toward the auditory area, six toward visual and seven toward tactile. In addition seven students who were high in one perceptual area had a tendency toward another.

\section{TABLE X}

STUDENTS WHOSE PERCEPTUAL PREFERENCE IN ONE OR MORE AREAS WERE BETWEEN 0.5 AND 1.0 STANDARD DEVIATION ABOVE THE MEAN (STANDARD SCORE $=55-59$ )

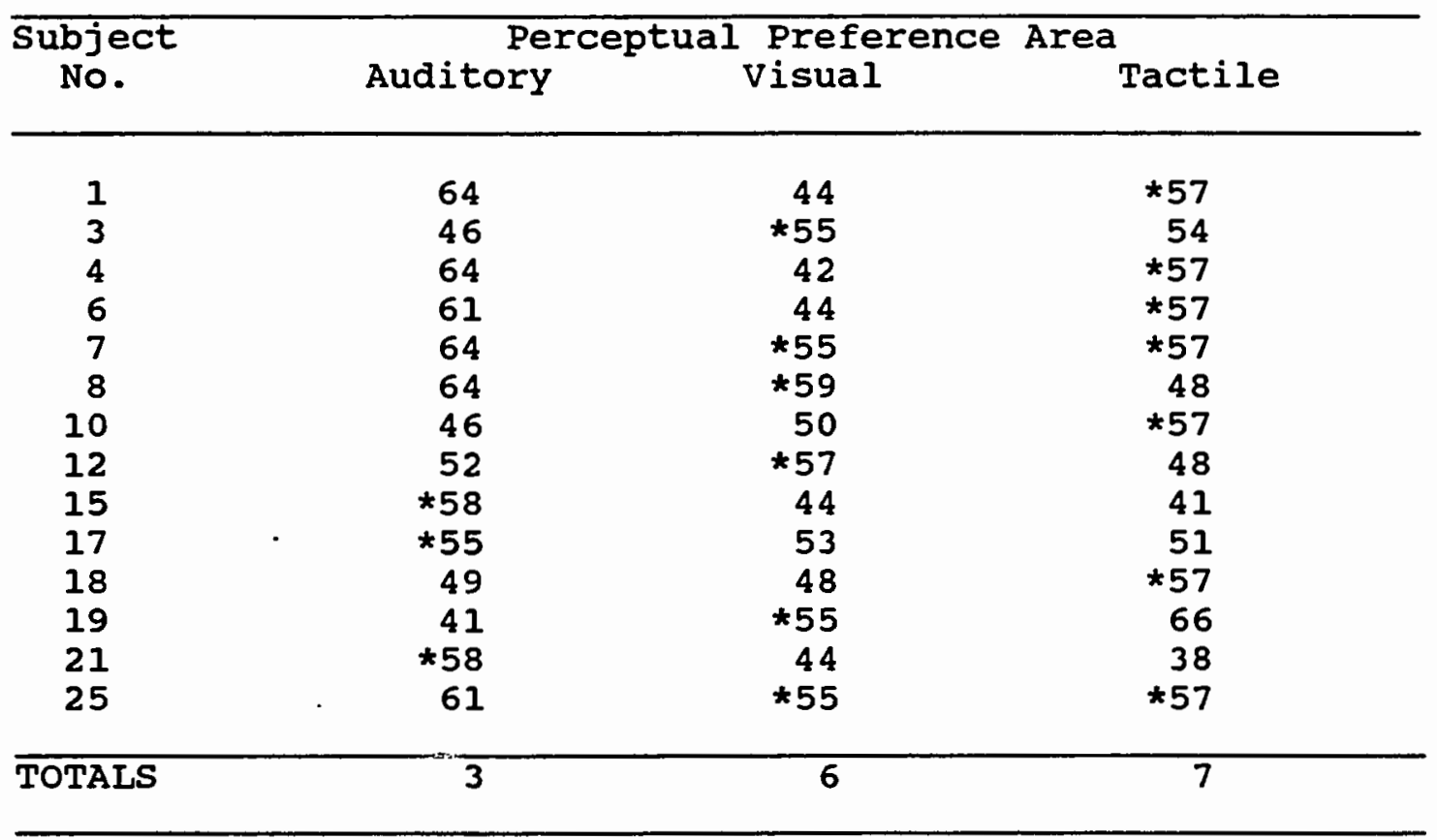

\section{Student Attitude Survey}

The Attitude Toward CAI Semantic Differential Tool developed by Allen (1986) was chosen to determine the attitudes of students toward the use of a computer program to 
supplement instruction (see Appendix B). Content validity of this tool was established by obtaining the rating of bipolar adjective pairs by five judges including four who are nationally known for their expertise in computer applications in nursing and one psychometrician with expertise in the development of semantic differential scales. Fourteen adjective pairs met the content/validity cricerion of $80 \%$ agreement among the judges, and constituted the final version of the Attitude Toward CAI Semantic Differential Tool. Factor analysis of the tool supported the contention that it primarily measures an evaluative component of attitude toward CAI. Rotated factors revealed clusters of adjectives which the author labeled evaluation of comfort, creativity and function (a combination of utility and relevance).

A sample of undergraduate nursing students was used to determine the reliability of the Attitude Toward CAI Semantic Differential Tool. Reliability was determined by computing cronbach's alpha coefficient of internal consistency reliability. Allen noted that for the total set of 14 semantic differential scores, all item-to-total correlations were positive and ranged from 0.308 to 0.634 . This supported the contention that the tool possesses an acceptable level of internal consistency reliability in the samples studied. Alpha coefficients of internal reliability for the 
three factors in undergraduate students were: comfort = 0.727 , creativity $=0.659$, and function $=0.784$.

The Attitude Toward CAI Semantic Differential Tool consists of 14 bipolar adjective pairs measured on a sevenpoint scale that reflects attitudes ranging from negative to positive. Therefore, each scale has a possible range of scores from 1 to 7 , with a score of 7 associated with the most positive attitude. The directions of the swales on the tool (from negative to positive) are randomly determined, and must be reversed for scoring purposes (see Appendix C). since this tool was just recently published, it has not been used in any studies published in the literature. Semantic differential scales have been used to determine student attitudes toward computer-assisted instruction (Day \& Payne, 1984; Gaston, 1988); however, the reliability and validity of those tools was not as well established as with the tool developed by Allen.

Additional questions were added to the attitude survey to determine if the mechanics of using the computer interfered with students' understanding of the program being used; if they had ever used a computer program as part of a class in the past; and if they thought Cardiac Exam Bingo added to their ability to learn the content about cardiac exam. 
STATISTICAL METHODS

The statistics obtained on all data from this investigation included Frequency Distributions, Pearson Product Moment correlations and the Chi square statistic. These statistical procedures were used to determine if a variety of relationships existed between the independent variable, perceptual preference learning style and the dependent variable, attitude scores on a semantic differential scale. 
CHAPTER IV

\section{RESULTS}

This investigation identified the perceptual learning style preferences of nursing students and examined the relationship between learning style perceptual preferences (auditory, visual or tactile) and students' attitudes toward the use of computer-assisted instruction. The areas of comfort, creativity and function provided the indicators for the students' experiences with the CAI program. The relationships between nursing students' perceptual learning style preferences and the following additional dependent variables were also examined:

1. The amount of time they spent using the computer program Cardiac Exam Bingo.

2. Whether the use of the computer program cardiac Exam Bingo added to the students' learning the content about the cardiac exam.

3. Whether the students wanted to have more use of computer-assisted instruction in the nursing program.

Hypotheses were examined using the Pearson Product Moment correlation and the chi square statistic. The independent variable was students' perceptual preference for auditory, visual or tactile learning. The dependent 
variables were the students' attitude scores on a semantic differential scale. The additional dependent variables were also examined for their relationship to the perceptual learning style preference.

\section{DISTRIBUTION OF SCORES ON THE PERCEPTUAL LEARNING STYLE PREFERENCE}

The mean and standard deviations on the auditory, visual and tactile learning style preferences of the sample of nursing students revealed a different distribution than those reported by Price, Dunn and Dunn (1982) (see Tables XI and XII). The means for the Price, Dunn and Dunn group were 50 on all three learning styles, whereas the means for the nursing students were 54.4 for auditory, 49.8 for visual and 54.9 for tactile. The standard deviations for the Price, Dunn and Dunn group were 10 on all three learning style preferences, whereas the standard deviations for the nursing students were 9.3 for auditory, 7.2 for visual and 7.5 for tactile. Since the PEPS was normed on a heterogenous sample of adults from several states and various academic and industrial settings, it is reasonable to expect different findings in the more homogenous sample of nursing students in a baccalaureate nursing program in the Pacific Northwest. The normal distribution for 83 subjects should result in 13 to 14 falling one standard deviation above the mean and 13 to 14 falling one standard deviation below it. 
TABLE XI

MEAN AND STANDARD DEVIATIONS FOR PERCEPTUAL LEARNING STYLE PREFERENCES REPORTED BY PRICE, DUNN AND DUNN (1982) FOR THE PEPS

\begin{tabular}{lll}
\hline Perceptual Preference & $\mathrm{x}$ & sd \\
\hline Auditory & 50 & 10 \\
Visual & 50 & 10 \\
Tactile & 50 & 10 \\
\hline
\end{tabular}

TABLE XII

MEAN AND STANDARD DEVIATIONS FOR PERCEPTUAL LEARNING STYLE PREFERENCES FOR 83 NURSING STUDENTS

\begin{tabular}{lcc}
\hline Perceptual Preference & $\mathrm{x}$ & sd \\
\hline Auditory & 54.4 & 9.3 \\
Visual & 49.8 & 7.2 \\
Tactile & 54.9 & 7.5 \\
\hline
\end{tabular}

The distribution of the subjects in this study was as follows: in the perceptual area of auditory learning, 15 were one standard deviation below the mean and 23 were one standard deviation above; in the perceptual area of visual learning, 17 were below and 19 above and in the area of tactile learning, 12 were below and 15 above. Because of the homogeneity of the sample, the transformation of the raw 
data into nominal data was made using the mean and standard deviations of the sample of nursing students rather than those reported by Price, Dunn and Dunn (1982) for the PEPS.

\section{DISTRIBUTION OF SCORES FOR THE DEPENDENT VARIABLES}

The same method was used to determine the mean and standard deviation for the subjects' attitudes in the areas of comfort, creativity and function (see Table XIII). It was also used to determine the mean and standard deviations of the data gathered about the amount of time students spent using the computer program Cardiac Exam Bingo and their responses on the Likert scales used to determine their attitudes about whether the use of the computer program added to their knowledge about the cardiac exam and whether they wanted more use of computer-assisted instruction in the nursing school curriculum (see Table XIV).

\section{TABLE XIII}

MEAN AND STANDARD DEVIATIONS FOR SUBJECTS' ATTITUDES

IN THE AREAS OF COMFORT, CREATIVITY AND FUNCTION

\begin{tabular}{|c|c|c|c|c|c|}
\hline Attitude & $\begin{array}{l}\text { Range } \\
\text { on Scale }\end{array}$ & $\mathbf{N}$ & $\begin{array}{l}\text { Range for } \\
\text { Student Responses }\end{array}$ & $x$ & $\mathbf{s d}$ \\
\hline Comfort & $4-28$ & 83 & $12-28$ & 23.2 & 4.1 \\
\hline Creativity & $4-28$ & 83 & $12-28$ & 19.9 & 3.8 \\
\hline Function & $6-42$ & 83 & $22-42$ & 34.6 & 5.0 \\
\hline
\end{tabular}


TABLE XIV

MEAN AND STANDARD DEVIATIONS FOR THE AMOUNT OF TIME STUDENTS SPENT USING THE COMPUTER PROGRAM; WHETHER THE USE OF THE COMPUTER PROGRAM ADDED TO THEIR KNOWLEDGE AND WHETHER THEY WANTED MORE USE OF CAI IN THE NURSING CURRICULUM

\begin{tabular}{lcccc}
\hline Variable & N & Range & $\mathrm{X}$ & sd \\
\hline Time & 81 & $5^{\prime \prime-150^{\prime \prime}}$ & 38.8 & 22.2 \\
$\begin{array}{l}\text { Added to } \\
\text { learning }\end{array}$ & 81 & $1-5$ & 4.1 & 0.8 \\
$\begin{array}{l}\text { More CAI in } \\
\text { curriculum }\end{array}$ & 81 & $1-5$ & 4.1 & 0.8 \\
\hline
\end{tabular}

PERCEPTUAL LEARNING STYLE PREFERENCES AND STUDENT ATTITUDES TOWARD COMPUTER-ASSISTED INSTRUCTION

The first statistical test performed on the data was the Pearson Product Moment Correlation. There were no significant correlations between perceptual learning styles and attitudes toward the use of the computer program, cardiac Exam Bingo. Nor were there any significant correlations between the perceptual learning styles and students' opinions about whether using the computer program added to their learning or whether they desired more use of computerassisted instruction in the nursing curriculum (see Table XV). There were similar non-significant findings when the time spent using the computer program was correlated with learning styles and students' attitudes. There were 
significant correlations between time spent using the computer program and the visual learning style and the attitudes of creativity and function (see Table XVI).

TABLE XV

CORRELATION MATRIX FOR MAJOR VARIABLES

Auditory Visual Tactile Cumfort Creativity Function Add More

\begin{tabular}{|c|c|c|c|c|c|}
\hline Auditory & 1.0 & & & & \\
\hline Visual & $-0.2047^{*}$ & 1.0 & & & \\
\hline Tactile & 0.1192 & 0.0566 & 1.0 & & \\
\hline Comfort & 0.1671 & -0.0225 & 0.1539 & 1.0 & \\
\hline Creativity & -0.0551 & 0.0029 & 0.0368 & $0.4536^{* *} 1.0$ & \\
\hline Function & -0.0041 & -0.0234 & 0.0646 & $0.5352^{* *} 0.7109^{* *}$ & $1.0^{-}$ \\
\hline Add & 0.0609 & 0.1066 & 0.1558 & $0.1544 \quad 0.3352^{* *}$ & $0.4661 * * 1.0$ \\
\hline $\begin{array}{l}\text { More } \\
\begin{aligned} * p< \\
* \star p<\end{aligned}\end{array}$ & $\begin{array}{l}0.0458 \\
05 \\
01\end{array}$ & -.0 .0189 & 0.0833 & $0.3491^{* *} 0.3653^{* *}$ & $0.6444^{* *} 0.4045^{* *} 1.0$ \\
\hline
\end{tabular}

TABLE XVI

CORRELATION MATRIX FOR TIME AND MAJOR VARIABLES

\begin{tabular}{rcccccc}
\hline & Auditory & Visual & Tactile & Comfort & Creativity & Function \\
\hline Time & 0.1500 & $0.2653^{* *}$ & 0.1491 & 0.1474 & $0.2310^{*}$ & $0.1951^{*}$ \\
$* p<0.05$ & & & & & \\
$* * \mathbf{p}<0.01$ & & & & & \\
\hline
\end{tabular}


Following transformation of the raw scores into nominal data, the chi square test was performed. None of the nine chi squares which compared learning styles and students' attitudes toward the use of the computer program had a $\mathrm{p}$ value that approached significance (see Tables XVII, XVIII and XIX). Nor did the chi squares show any significance between learning styles and students' opinions about whether the computer program added to their learning or whether they desired more computer-assisted instruction in the nursing curriculum (see Tables XX and XXI).

TABLE XVII

RESULTS OF THE CHI SQUARE COMPARING STUDENT PERCEPTUAL PREFERENCES TO STUDENTS ' ATTITUDE, COMFORT

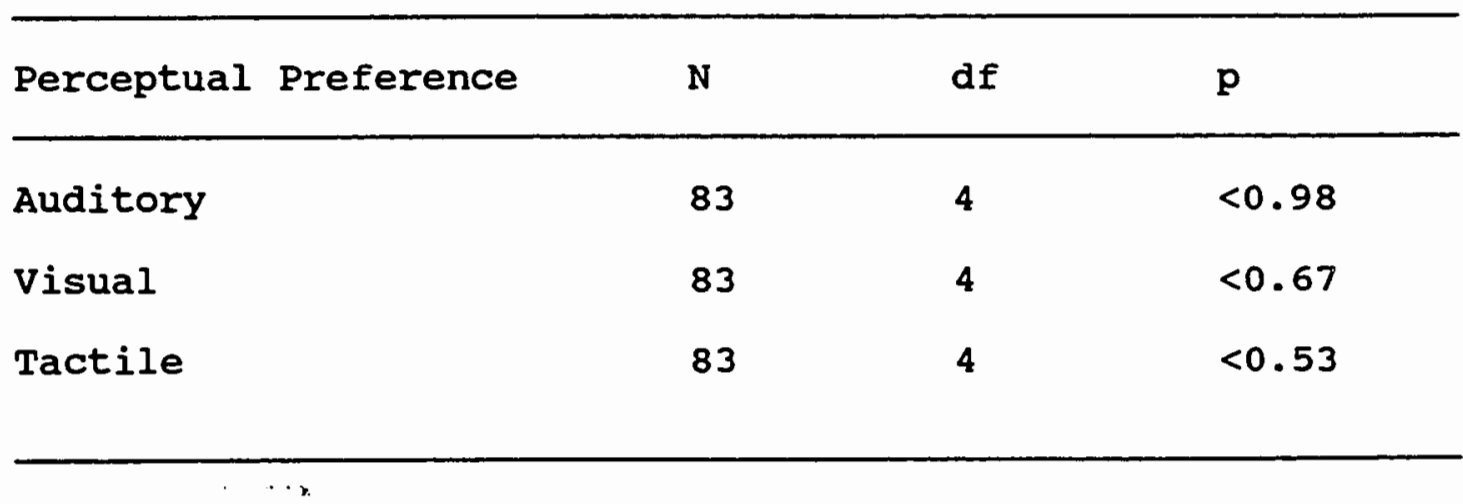

The chi square statistic was also used to examine the relationship between the amount of time spent using the computer, and the following: perceptual learning styles (see Table XXII), students' attitudes toward the use of the computer program (see Table XXIII) and their opinions about 
its adding to their learning and their desiring more use of CAI in the nursing curriculum (see Table XXIV). In these analyses, time was categorized by using the mean and standard deviation to determine high, middle and low groups. The high group consisted of all students who spent $60-120$ minutes using Cardiac Exam Bingo ( $N=19$ ), the middle group spent 18-48 minutes $(N=53)$ and the low group spent 5-15 minutes $(\mathrm{N}=19)$. A second analysis was done dividing the subjects into two groups. Group one consisted of all students who spent 5-30 minutes using Cardiac Exam Bingo (N $=46$ ) and group two consisted of those who spent from 35-150 minutes $(\mathrm{N}=35)$.

TABLE XVIII

RESULTS OF THE CHI SQUARE COMPARING STUDENT PERCEPTUAL PREFERENCES TO STUDENTS ' ATTITUDE, CREATIVITY

\begin{tabular}{lccc}
\hline Perceptual Preference & N & df & p \\
\hline Auditory & 83 & 4 & $<0.55$ \\
Visual & 83 & 4 & $<0.61$ \\
Tactile & 83 & 4 & $<0.12$ \\
\hline
\end{tabular}


TABLE XIX

RESULTS OF THE CHI SQUARE COMPARING STUDENT

PERCEPTUAL PREFERENCES TO STUDENTS'

ATTITUDE, FUNCTION

\begin{tabular}{lccc}
\hline Perceptual Preference & N & df & p \\
\hline Auditory & 83 & 4 & $<0.92$ \\
visual & 83 & 4 & $<0.47$ \\
Tactile & 83 & 4 & $<0.12$ \\
\hline
\end{tabular}

TABLE XX

RESULTS OF THE CHI SQUARE COMPARING STUDENT PERCEPTUAL

PREFERENCES TO STUDENTS' OPINIONS ABOUT WHETHER

THE USE OF THE COMPUTER PROGRAM

ADDED TO THEIR LEARNING

\begin{tabular}{|c|c|c|c|}
\hline Perceptual Preference & $\mathbf{N}$ & $d f$ & $\mathbf{p}$ \\
\hline Auditory & 83 & 4 & $<0.25$ \\
\hline Visual & 83 & 4 & $<0.49$ \\
\hline Tactile & 83 & 4 & $<0.82$ \\
\hline
\end{tabular}

When divided into high, middle and low groups using the mean and standard deviation, there was a statistically significant relationship between time and student attitudes in the area of function. students who spent the most time using the computer program had a more positive attitude toward the function of the computer (i.e. its utility and 
relevance). There was also statistical significance between the amount of time spent and whether the use of computerassisted instruction should be added to the nursing curriculum (see Tables XXII, XXIII, and XXIV).

TABLE XXI

RESULTS OF THE CHI SQUARE COMPARING STUDENT PERCEPTUAL PREFERENCES TO STUDENTS ' OPINIONS ABOUT WHETHER THEY WANTED MORE CAI IN THE CURRICULUM

\begin{tabular}{lccc}
\hline Perceptual Preference & N & df & p \\
\hline Auditory & 83 & 4 & $<1.0$ \\
Visual & 83 & 4 & $<0.91$ \\
Tactile & 83 & 4 & $<0.75$ \\
\hline
\end{tabular}

TABLE XXII

RESULTS OF THE CHI SQUARE COMPARING STUDENT PERCEPTUAL PREFERENCE WITH THE AMOUNT

OF TIME SPENT USING THE COMPUTER PROGRAM WHEN TIME WAS DIVIDED USING THE MEAN AND STANDARD

DEVIATION

\begin{tabular}{lccc}
\hline Perceptual Preference & N & df & p \\
\hline Auditory & 81 & 4 & $<0.73$ \\
Visual & 81 & 4 & $<0.11$ \\
Tactile & 81 & 4 & $<0.73$ \\
\hline
\end{tabular}


TABLE XXIII

RESULTS OF THE CHI SQUARE COMPARING STUDENT ATTITUDES TOWARD CAI WITH THE AMOUNT OF TIME SPENT USING THE COMPUTER PROGRAM WHEN TIME WAS DIVIDED USING THE MEAN AND STANDARD DEVIATION

\begin{tabular}{llll}
\hline Student Attitude & N & df & p \\
\hline Comfort & 81 & 4 & $<0.25$ \\
Creativity & 81 & 4 & $<0.58$ \\
Function & 81 & 4 & $<0.04$ \\
\hline
\end{tabular}

TABLE XXIV

RESULTS OF THE CHI SQUARE COMPARING STUDENTS' OPINION ABOUT WHETHER USE OF THE COMPUTER PROGRAM ADDED TO THEIR I.EARNING AND WHETHER THEY WANTED MORE CAI IN THE CURRICULUM WITH THE AMOUNT OF TIME SPENT USING THE COMPUTER PROGRAM WHEN TIME WAS DIVIDED USING THE MEAN AND STANDARD DEVIATION

\begin{tabular}{lccc}
\hline Student opinion & N & df & p \\
\hline Added to learning & 81 & 4 & $<0.000$ \\
More CAI in curriculum & 81 & 4 & $<0.30$ \\
\hline
\end{tabular}

When students were divided into the two groups, there were two statistically significant relationships. The relationship between the amount of time spent using the computer program and students' visual perceptual learning style was significant $p=.05$. There was also a statistically 
significant relationship between the amount of time students spent using the computer program, and whether they believed its use added to their learning $p=.04$. In addition, the relationship between time and students' attitudes toward function approached significance $p=.06$ (see Tables $x X V$, XXVI, and XXVII).

TABLE XXV

RESULTS OF THE CHI SQUARE COMPARING STUDENT PERCEPTUAL PREFERENCE WITH THE AMOUNT OF TIME SPENT USING THE COMPUTER PROGRAM WHEN TIME WAS DIVIDED INTO TWO GROUPS

\begin{tabular}{lccc}
\hline Perceptual Preference & N & df & p \\
\hline Auditory & 81 & 2 & $<0.86$ \\
Visual & 81 & 2 & $<0.05$ \\
Tactile & 81 & 2 & $<0.86$ \\
\hline
\end{tabular}

TABLE XXVI

RESULTS OF THE CHI SQUARE COMPARING STUDENT ATTITUDES

TOWARD CAI WITH THE AMOUNT OF TIME SPENT USING

THE COMPUTER PROGRAM WHEN TIME WAS

DIVIDED INTO TWO GROUPS

\begin{tabular}{lccc}
\hline Student Attitude & N & df & p \\
\hline Comfort & 81 & 2 & $<0.76$ \\
Creativity & 81 & 2 & $<0.96$ \\
Function & 81 & 2 & $<0.06$ \\
\hline
\end{tabular}


TABLE XXVII

RESULTS OF THE CHI SQUARE COMPARING STUDENTS' OPINION ABOUT WHETHER USE OF THE COMPUTER PROGRAM ADDED TO THEIR LEARNING AND WHETHER THEY WANTED MORE CAI IN THE CURRICULUM WITH THE AMOUNT OF TIME SPENT USING THE COMPUTER PROGRAM WHEN TIME WAS

DIVIDED INTO TWO GROUPS

\begin{tabular}{lccl}
\hline Student opinion & N & df & p \\
\hline Added to Learning & 81 & 2 & $<0.04$ \\
More CAI in Curriculum & 81 & 2 & $<0.62$ \\
\hline
\end{tabular}

After reviewing the data gathered about the perceptual learning styles of auditory, visual and tactile, this investigator decided to look at each individual student's score on all three perceptual learning styles. A frequency distribution of the data revealed that there were 22 different combinations of scores ranging from one student being low in all three learning styles to two students being high in all three. Since the literature about the PEPS indicates that students who are both tactile and visual might do well with the use of computers or learning methods that required tactile stimulation, chi squares were done to determine if there was a relationship between students who scored in the mid range or higher on both visual and tactile learning styles and their attitudes in the areas of comfort, 
creativity and function. There were no significant findings when the data were analyzed in this way (see Table XXVIII).

TABLE XXVIII

RESULTS OF THE CHI SQUARE COMPARING STUDENTS WHO SCORED

IN THE MIDDLE OR HIGH RANGES ON BOTH THE VISUAL

AND TACTILE PERCEPTUAL LEARNING STYLES

AND THEIR ATTITUDES IN THE AREAS

OF COMFORT, CREATIVITY

AND FUNCTION

\begin{tabular}{lccc}
\hline Student Attitude & N & df & p \\
\hline Comfort & 81 & 2 & $<0.86$ \\
Creativity & 81 & 2 & $<0.21$ \\
Function & 81 & 2 & $<0.68$ \\
\hline
\end{tabular}

since the data collected on the 14 items on the semantic differential scale were grouped into the three categories of comfort, creativity and function, each of the 14 items on the semantic differential scale were looked at individually. The mean and standard deviations of each of the 14 items on the semantic differential scale are shown on Table XXIX. When each of these items is examined individually, 13 have a mean score higher than the mid-point (4) on the scale which ranges from 1 (low) to 7 (high) and one, personal/impersonal, is lower at 3.7. This finding is not surprising, since the three attitudes of comfort, creativity and function which were determined using these 14 items had 
mean scores higher than would be expected in a normal distribution. The Pearson Product Moment Correlation was used to determine if there was any relationship between the perceptual learning styles and one or more of the items on the semantic differential. This analysis revealed that there was a significant correlation between visual learning and the attitude that the use of computer-assisted instruction was flexible $(p=0.006)$. There was also a significant correlation between visual learning and the attitude that the use of computer-assisted instruction was personal ( $p=$ $0.02)$. There were significant correlations between tactile learning and the attitude that the use of computer-assisted instruction was meaningful $(p=0.004)$, pleasant $(p=0.04)$ and easy to use $(p=0.02)$.

TABLE XXIX

MEAN AND STANDARD DEVIATIONS OF ATTITUDES OF 83 NURSING STUDENTS TOWARD CAI

\begin{tabular}{lll} 
Attitude & $\mathrm{x}$ & $\mathrm{sd}$ \\
\hline Flexible vs. rigid & 5.2 & 1.5 \\
Useful vs useless & 6.0 & 1.0 \\
Stimulating vs. boring & 5.6 & 1.2 \\
Meaningful vs meaningless & 5.7 & 1.2 \\
Pleasant vs unpleasant & 5.7 & 1.1 \\
Valuable vs. worthless & 6.0 & 1.1 \\
Creative vs unimaginative & 5.5 & 1.2
\end{tabular}


TABLE XXIX

$$
\begin{aligned}
& \text { MEAN AND STANDARD DEVIATIONS OF ATTITUDES OF } \\
& 83 \text { NURSING STUDENTS TOWARD CAI } \\
& \text { (continued) }
\end{aligned}
$$

\begin{tabular}{lll}
\hline Attitude & $x$ & sd \\
\hline Personal vs. impersonal & 3.7 & 1.7 \\
Efficient vs. inefficient & 5.8 & 1.0 \\
Appropriate vs inappropriate & 6.0 & 1.0 \\
Comfortable vs. uncomfortable & 5.8 & 1.3 \\
Non-threatening vs. threatening & 5.8 & 1.7 \\
Easy to use vs. overpowering & 6.0 & 1.3 \\
Time saving vs. time consuming & 5.1 & 1.5 \\
\hline
\end{tabular}

SUMMARY

The statistical analyses used to test the hypotheses all revealed that there was no relationship between student satisfaction with computer-assisted instruction and perceptual learning style characteristics. In addition, there were no significant findings when the data were analyzed by grouping students who were in the mid range or higher in the visual and tactile learning styles. Therefore, all of the following hypotheses were rejected:

1. There will be a statistically significant negative correlation between auditory perceptual learning style and 
attitude toward computer-assisted instruction in the area of comfort.

2. There will be a statistically significant negative correlation between auditory perceptual learning style and attitude toward computer-assisted instruction in the area of creativity.

3. There will be a statistically significant negative correlation between auditory perceptual learning style and attitude toward computer-assisted instruction in the area of function.

4. There will be a statistically significant positive correlation between visual perceptual learning style and attitude toward computer-assisted instruction in the area of comfort.

5. There will be a statistically significant positive correlation between visual perceptual learning style and attitude toward computer-assisted instruction in the area of creativity.

5. There will be a statistically significant positive correlation between visual perceptual learning style and attitude toward computer-assisted instruction in the area of function.

7. There will be a statistically significant positive correlation between tactile perceptual learning style and attitude toward computer-assisted instruction in the area of comfort. 
8. There wili be a statistically significant positive correlation between tactile perceptual learning style and attitude toward computer-assisted instruction in the area of creativity.

9. There will be a statistically significant positive correlation between tactile perceptual learning style and attitude toward computer-assisted instruction in the area of function.

The statistical analysis used to compare the perceptual learning styles with the two additional variables of whether the computer program Cardiac Exam Bingo added to the students' learning the content about the cardiac exam and whether the students wanted to have more use of computerassisted instruction in the nursing program did not reveal any statistically significant relationships. However, when the relationship between the variable of the amount of time students spent using the computer program and perceptual learning styles was analyzed, a significant correlation was found between time and the visual perceptual learning style. STUDENT RESPONSES TO OPEN ENDED QUESTIONS

Additional questions were added to the attitude survey to determine if the mechanics of using the computer interfered with students' understanding of the program being used, if they had ever used a computer program as part of a 
class before and if they had any additional comments about this experience.

When asked if the mechanics of using the computer interfered with their understanding of the program they were using, eight of the eighty-three responded yes. Seven of the eight made additional comments. One indicated the problem was with the computer itself noting that, "It took a while to get started and get the 'hang' of operating the computer." The other six students' comments were related to their reading and understanding the directions that accompanied Cardiac Exam Bingo.

Seventy-five of the 83 students had used a computer before. When asked to describe their use, those who responded listed word processing (37), high school or college classes (22) and a variety of other uses including games, programming and use in their job.

of the 81 students who responded to the question, "Have you ever used a computer as part of a class before?", 43 responded yes and 38 said no. Thirty-eight students responded to the request to describe their experience with this program compared to previous experiences. A list of all of those responses can be found in Appendix D. Comments students made were too varied to provide a common theme. Perhaps the reason for this is the wide variety of previous experiences. Nine students noted that this program was more simplistic or easier; five commented that it was more 
enjoyable and seven thought it was a good learning experience, a learning process or teaching oriented. Other responses ranged from critiques of previous programs, comparative comments and a description of past experiences. Qualitative data were gathered in response to an open ended request for additional comments. Thirty-seven of the 83 students ( $45 \%$ ) made 47 comments which fell into one of the following four areas:

- The computer program Cardiac Exam Bingo

- The use of computers for education (13)

- The facilities--Instructional Media Department (3)

- Affective comments about personal learning (17)

A list of all of the students' comments can be found in Appendix E. A summary of their comments follows.

\section{The Computer Program Cardiac Exam Bingo}

Most students made suggestions related to the questions asked in the program. They wanted more questions, a wider variety of questions, an expanded version of the game and at the end of the game to be given a list of questions missed. One student thought it would be helpful to have a program such as this for all of the systems taught during the course (i.e. respiratory, gastrointestinal, reproductive etc.) 
The Use of the Computer in Education

Most of the comments about the use of computerassisted instruction in education were positive such as:

"This is an excellent way to test my knowledge . . ."

"Good approach . . . "

"I think it is a good idea . . ."

However, 6 of the 13 students who commented recommended that computer programs be available but not required:

". . it should be an option, not required."

". . to make it required would be a mistake . ."

"I don't think it should be required although it is good to have available as a study tool."

Four students who made favorable comments about the use of computer-assisted instruction noted that there was little study time left for them to add the use of it to their already busy schedule. Comments such as these indicate that the academic and clinical work load in the nursing program may be a factor in students' recommending that computer programs be available but not required.

\section{The Facilities (Instructional Media Department)}

The Instructional Media Department used by the students has a limited amount of space and only three Apple IIE computers. Comments about the facilities were expected, yet only three comments were made about the facility and only two were negative. 


\section{Affective Comments About Personal Learning}

It was interesting to note that of the 17 comments in this category only one was negative. The comment, "I will never enjoy looking at a computer screen" was preceded by the statement "Good program." Two other students who stated that the use of a computer was not their most effective way of learning made positive comments about it.

\section{SUMMARY}

The qualitative data gathered by giving students an opportunity to make additional comments has added to the richness of the data. The affective comments provided further evidence that students had very positive attitudes toward the CAI program used for this study. While only 17 students made comments in this area, 16 were positive and the 17th student who stated that she did not like looking at a computer screen thought it was a good program.

The comments about the use of computer programs in education revealed that students had a positive attitude toward the use of computers regardless of their perceptual learning style. Six of the 13 students commenting suggested that the use of computer-assisted instruction be available but not required. 


\section{CHAPTER V \\ DISCUSSION, CONCLUSIONS, RECOMMENDATIONS}

This study investigated the relationship between the perceptual learning style preferences of nursing students and their attitudes toward computer-assisted instruction. In addition, it looked at the relationships between nursing students' perceptual learning style preferences, and three additional dependent variables, the amount of time they spent using the computer program Cardiac Exam Bingo, whether the use of the computer program added to their learning the content about the cardiac exam and whether students wanted to have more use of CAI in the nursing program.

An answer was sought to the following question: will there be significant correlations between students who have:

1. an auditory perceptual preference and negative attitudes toward CAI?

2. a visual perceptual preference and positive attitudes toward CAI?

3. a tactile perceptual preference and positive attitudes toward CAI? 


\section{DISCUSSION}

Previous research has demonstrated that students had positive attitudes toward computer-assisted instruction in elementary and secondary settings (Jamison et al., 1974; Kulik, Bangert, Williams, 1983; Rappaport \& Savard, 1980; Thomas, 1978; Wilson, 1980) (see Table III). Results from eleven studies which investigated computer-assisted instruction at the college level found that attitudes toward computer-assisted instruction in eight of the studies were higher than those toward conventional classes (Kulik, Kulik, \& Cohen, 1980). Although small in number, a majority of the studies in the nursing literature that looked at attitudes toward CAI also cited more that found positive attitudes toward CAI than did not (Bitzer, 1966; Bitzer \& Bitzer, 1973; Conklin, 1983; Hoffer et al., 1975; Kirchoff \& Holzemer, 1979; Schleutermann et al., 1983; Timpke \& Janney, 1981; Valish \& Boyd, 1975).

In the nursing literature, students' attitudes toward CAI were reported as anecdotal in response to open-ended questions. When specific tools were used in quantitative studies, the psychometric properties of the variety of tools used were often not validated. In addition, when researchers found that students had positive attitudes toward CAI, they could not identify any specific reasons for them. 
The only reported research that investigated the relationship between computer-assisted instruction (CAI) and perceptual learning style preferences was performed on seventh grade students (Martini, 1986). In that study, instructional methods were matched and mismatched according to students' perceptual learning style preferences. While all students who had their instruction matched to their learning style scored consistently higher than those who did not, all students regardless of their learning style had more positive attitudes toward CAI than to the other instructional methods used (i.e., cassette tapes and printed materials). In addition, Martini reported that regardless of the students' perceptual preference, all students scored highest when taught through computer-assisted instruction. Even though attitudes were examined in previous studies, researchers did not identify any specific reasons for positive attitudes. This investigator hypothesized that perceptual learning styles might be a factor that could distinguish between students who had a positive attitude and those who did not.

The authors of the learning style inventory (PEPS) used in this study recommend the use of computers for individuals with visual preferences and touchable and moveable as well as readable resources for those identified as having a tactile preference. The use of materials such as audiotapes and records is recommended for auditory preferenced 
learners. The findings from this study similar to those from Martini's do not confirm the idea that students with an auditory learning style would be less interested in using computer-assisted instruction.

All students regardless of their perceptual learning style preference had positive attitudes toward the use of computer-assisted instruction with a range of mean scores above what might be expected in a normal distribution (see Table XIII). Therefore, there was no significant relationship between any one of the learning styles and students' attitudes toward CAI. The reasons for this are not clear. One might speculate that the use of the computer was a novelty. However, in the discussion of her study, Martini noted that the use of computers was not a novelty to her subjects. Each had been enrolled in computer classes at least one year prior to the study. Nursing students in this study were also familiar with the use of computers. Seventy-five of the eighty-three students had used a computer before in a variety of activities from the use of computers as part of a college class to their use for relaxation in the form of games. Gaston (1988) found that students had a more positive attitude toward CAI than toward the lecture method of instruction. She speculated that student orientation to the use of CAI or the attitudes of the orientation faculty might have been critical factors in developing positive students attitudes. In this study, students were 
not oriented to the use of the computer nor did this investigator describe the positive aspects of computer-assisted instruction.

Previous research reported in review articles looked at the effect of computer-assisted instruction on the amount of time it took to complete course material using CAI compared to traditional instruction (Edwards et al., 1975; Jamison, Suppes, \& Wells, 1974; Kulik, Bangert, \& Williams, 1983; Kulik, Kulik, \& Cohen, 1980; Thomas, 1978; Wilson, 1980). In all of the studies reviewed by these authors, the use of CAI resulted in a saving of student time. This investigation did not look at computer-assisted instruction as a time saver for students. students were only asked how much time they spent using the computer program. Data analysis in this study showed significant positive correlations between time spent using the computer and the visual perceptual learning style; the attitude of function; whether students felt the use of the computer program added to their knowledge about the cardiac exam and whether they wanted more CAI added to the nursing curriculum.

The significant correlation between the visual perceptual learning style and the amount of time students spent using Cardiac Exam Bingo might indicate that visual learners enjoyed or felt more positive about using the computer program than auditory or tactile learners. Without more data, one should be cautious about making this assumption. 
The significant relationship between the amount of time students spent using the program and their attitude toward function should also be viewed cautiously.

The significant relationship between the amount of time spent using the computer program, whether students felt use of the program added to their knowledge about the cardiac exam and whether they wanted more CAI added to the curriculum is what one might expect. However, the qualitative data revealed that some students considered the use of the CAI program as an "add on" rather than a time saver. The qualitative data gathered when students were asked to make comments about their experience using Cardiac Exam Bingo provide additional useful information. The comments about the use of computers in education indicated that students found the computer program to be a useful study tool. However, there was concern that its required use would add to students' work load. The nursing students' academic work load as well as the time spent in clinical courses is extensive. students in this study said that even though they enjoyed using a computer-assisted instruction program they could not support the idea of it being added to an already busy academic schedule. Nursing faculty who are planning to incorporate CAI into their courses should consider how this can be done without increasing student work load. Perhaps providing choices to students would give them 
the option of selecting the instructional methods that best suit their individual learning needs.

The positive affective comments about the computer program were not only helpful in assessing the usefulness of computer-assisted instruction but also made this investigator feel that the development of a program like Cardiac Exam Bingo is worthwhile.

\section{IMPLICATIONS FOR NURSING EDUCATION}

The findings from this study can be useful to nursing eduçators as they continue to recognize that computers are useful tools for student education. While there were no significant correlations between perceptual learning styles and students' attitudes toward computer-assisted instruction in this study, the data clearly showed that all students' attitudes toward CAI were higher than what would be expected in a normal distribution. This finding along with those of Bitzer (1960), Conklin (1983), Gaston (1988), and Timpke and Janney (1981) indicate that nursing educators could expect that nursing students would have a positive attitude toward the incorporation of computer-assisted instruction into nursing courses. The important question of whether computer programs should be required or be made available is one that needs further study. The results of this investigation based on perceptual learning styles do not provide any data to help answer this question. However, the qualitative data 
indicate that though students had positive attitudes toward CAI, several recommended that it not be required. Until further study can be done in this area, faculty should be cautious about requiring students to use computer-assisted instruction as part of a course requirement. Since students were also concerned about not having enough time to spend using a computer program, CAI should be included as part of a course only after consideration is given to the time it takes students to complete all assignments. Until more conclusive data are available, faculty might consider including a CAI program as one of many options available to enhance student learning.

The findings of researchers who looked at the role of computer-assisted instruction in increasing achievement scores must not be forgotten. While this study did not address this issue, other researchers have established that students have attained higher achievement using CAI at elementary, secondary and college levels (Edwards et al., 1975; Jamison, Suppes, \& Wells, 1974; Kulik, Kulik, \& Cohen, 1980; Rappaport \& Savard, 1980; Thomas, 1978; Wilson, 1980). Similar findings were reported in the nursing literature by Bitzer (1966), Conklin (1983) and Hoffer et al. (1975). More than ever before, rapid technological advances will likely affect the way college students are taught. studies have already shown that computer-assisted instruction is an effective adjunct to traditional methods of 
instruction (Edwards et al., 1985; Jamison, Suppes, \& Wells, 1974; Kulik, Bangert, \& Williams, 1983; Rappaport \& Savard, 1980; Thomas, 1978; Wilson, 1980). Students have positive attitudes toward its use and some studies have shown that comparisons of CAI with traditional instruction produce equal or better achievement in less time.

Traditionally, college professors have preferred the lecture/discussion method of teaching. While discussing the traditionalism of college professors, clark Kerr (1976) has said, "You could go back to the University of Bologna in the 12th century and feel more or less at home." Professors of nursing have been somewhat more inclined to use new technologies because of the need to teach students clinical skills. Audio-visual equipment such as slide-tape presentations, film strips, films and videotapes have been used for several years in schools of nursing. However, the use of computers in nursing education has been slow to develop in part because of limited and often poorly designed software, inadequate numbers of machines and a limited number of computer literate faculty (Murphy, 1987).

As nursing professors become more involved in the development of computer programs, including interactive video, the quality of software should improve. Once that occurs, there may be more use of CAI in nursing courses. Courses could be planned so that the use of computerassisted instruction would give faculty more time to 
interact with students and help them with reasoning and critical thinking skills. If this occurred, computers could contribute to an increase in the effectiveness of instruction in schools of nursing.

\section{CONCLUSIONS}

No positive correlations between learning styles and attitudes toward CAI were found. When each item on the semantic differential scale was examined individually, there was a significant correlation between visual learning and the attitude that the use of CAI was rigid and impersonal. There were also significant correlations between tactile learning and the attitudes that the use of CAI was meaningful and easy to use.

The three additional dependent variables examined revealed that there was a significant relationship between the amount of time spent using the computer program and the visual perceptual learning style, i.e. the students with a visual learning style preference spent more time using the CAI program. In addition, the relationship between the amount of time spent using the computer program and the attitude toward function is unclear. There was statistical significance between time and function when time was divided into three groups (high, middle and low) but only approached significance when time was divided into high and low groups. 
Significant correlations were also found between time and whether students felt the use of the computer program added to their knowledge about the cardiac exam and whether they wanted more computer-assisted instruction in the nursing curriculum.

\section{RECOMMENDATIONS FOR FUTURE RESEARCH}

As an outgrowth of the findings of this investigation, the following recommendations are made for future research. A study should be designed to examine students' learning styles, their use of computer-assisted instruction as part of a theoretical nursing course, their attitudes toward CAI and academic achievement. Since this study did not include students' achievement, it would be interesting to determine if there is a relationship between academic achievement and perceptual learning styles when computer-assisted instruction has been used. It would be helpful to know if students' attitudes toward CAI along with their perceptual learning styles could be predictive of student achievement.

It would also be interesting to look at the relationship between students' perceptual learning styles, and their clinical performance to determine if students' clinical performance could be predicted using perceptual learning styles. In addition, it would be helpful to know the effect, if any, of students' use of computer simulations of clinical nursing problems on their ability to practice in 
clinical settings. Are they able to transfer learning to clinical practice when computer-assisted instruction is used?

An additional area of interest is students' short- and long-term retention of material learned using CAI versus traditional methods of instruction. The effect of the use of CAI on achievement has been studied at all levels of education including nursing. However, its effect on retention has not. Since nursing is a profession in which knowledge is built upon and incorporated into clinical practice, retention of what has been learned is critical. If the use of computer clinical simulations could be shown to increase retention, its value to nursing education would be assured. 
REFERENCES

Allen, I. R. (1986) . Measuring attitude toward computer assisted instruction. Computers in Nursing, $4,144-$ 151 .

Alpert, D., \& Bitzer, D. I. (1970). Advances in computer based education. Science, 167, 1,582-1,590.

Bane, C. L. (1925). The lecture vs. the class-discussion method of college teaching. School and Society, 532, 300-302.

Bitzer, M. (1966). Clinical nursing instruction via the Plato simulated laboratory. Nursing Research, 15, 144-150.

Bitzer, M. D., \& Bitzer, D. L. (1973). Teaching nursing by computer: An evaluative study. Computers in Biology and Medicine, $\underline{3}$, 187-204.

Bitzer, M. P., \& Boudreau, M. C. (1969). Using a computer to teach nursing. Nursing Forum, 3 , 234-254.

Boettcher, E. G., Alderson, S. F., \& Saccucci, M. S. (1981). Comparison of the effects of computerassisted instruction versus printed instruction on student learning in the cognitive categories of knowledge and application. Journal of Computer-Based Instruction, $8,13-17$.

Canfield, A. A., \& Lafferty, J. C. (1970). Learning styles inventory. Detroit: Humanics Media (Liberty Drawer 7970).

Cafferty, E. (1980). An analysis of student performance based upon the degree of match between the educational cognitive style of the teachers and the educational cognitive style of the students. Dissertation $A B-$ stracts International, 41, 2908A. (University Microfilms No. 81-01,213) 
Carbo, M. A. (1980). An analysis of the relationships between the modality preferences of kindergartners and selected reading treatments as they affect the learning of a basic sight-word vocabulary (Doctoral dissertation, st. John's University, 1980). Dissertation Abstracts International, 41, 1389A.

Christiansen, M., Lee, P., \& Bugg, P. (1979). Professional development of nurse practitioners as a function of need motivation, learning style and locus of control. Nursing Research, 28, 51-56.

Conklin, D. N. (1983). A study of computer-assisted instruction in nursing education. Journal of ComputerBased Instruction, 9, 98-107.

Copenhaver, R. (1979). The consistency of student learning styles as students move from English to mathematics. Dissertation Abstracts International, 40, 3735A. (University Microfilms No. 80-00,610)

Cross, K. P. (1976). Accent on learning. San Francisco: Jossey-Bass, Inc.

Cupke, J. A. (1980). The effects of similarity of instructor preferred teaching style on student achievement in selected courses in a metropolitan community college. Dissertation Abstracts International, 41, 998A. (University Microfilms No. 80-19,137)

Day, R. , \& Payne, L. (1984). Comparison of lecture presentation versus computer managed instruction. Computers in Nursing, $2,236-240$.

DeBello, T. (1985). A critical analysis of the effects on achievement and attitudes of administrative assignments to social studies instruction based on individual, eighth grade students' sociological preferences for learning alone, with peers, or with teachers. Unpublished doctoral dissertation, st. John's University, Brooklyn.

Della Valle, J. (1984) . An experimental investigation of the relationship(s) between preference for mobility and the word recognition scores of seventh grade students to provide supervisory and administrative quidelines for the organization of effective instructional environments. Unpublished doctoral dissertation, st. John's University, Brooklyn. 
Dick, W. J. (1968). A methodology for the formative evaluation of instructional materials. Journal of Educational Measurement, $\underline{5}$ (2), 99-102.

Domino, G. (1970). Interactive effects of achievement orientation and teaching style on academic achievement. ACT Research Report, 39, 1-9.

Dubin, R., \& Taveggia, T. C. (1968). The teaching learning paradox. Eugene, OR: University of Oregon Press.

Dunn, R. (1982). Teaching students through their individual learning styles: A research report. In $J$. Keefe (Ed.), student learning styles and brain behavior (pp. 142-151). Reston, VA: National Association of secondary school Principals.

Dunn, R. (1983, January). You've got style. Now's the time to find out what it is. Early Years, 13 (5), 23$31,58-59$.

Dunn, R. (1984, winter). Learning style: state of the science. Theory Into Practice, 23 (1), 10-19.

Dunn, R. \& Carbo, M. (1981, February). Modalities: An open letter to Walter Barbe, Michael Milone and Raymond Swassing. Educational Leadership, 38 (5), 381382 .

Dunn, R., DeBello, T., Brennan, P., Krimsky, J., \& Murrain, P. (1981). Learning style researchers define differences differently. Educational Leadership, 38, $372-375$.

Dunn, R., \& Dunn, K. (1972) . Practical approaches to individualizing instruction: Contrasts and other effective strategies. West Nyack, NY: Parker Publishing Company.

Dunn, R., \& Dunn, K. (1975). Learning styles, teaching styles. NASSP Bulletin, 59 (393), 37-49.

Dunn, R., \& Dunn, K. (1977). Administrator's guide to new programs for faculty management and evaluation. West Nyack, NY: Parker Publishing Company.

Dunn, R., \& Dunn, K. (1978). Teaching students through their individual learning styles: A practical approach. Reston, VA: Reston Publishing Company. 
Dunn, R., \& Dunn, K. (1979). Learning styles/teaching styles: Should they . . can they . . be matched? Educational Leadership, 36, 49, 243.

Dunn, R., Dunn, K., \& Price, G. (1976). Learning as a matter of style. New York School Administrator's Journal, $6(2), 11-12$.

Dunn, R., Dunn, K. , \& Price, G. (1978). Learning style inventory. Lawrence, KS: Price systems.

Dunn, R., Dunn, K. \& Price, G. (1981). Productivity environmental preference survey. Lawrence, KS: Price systems.

Dunn, R., Dunn, K., \& Price, G. (1986). Productivity environmental preference survey. Lawrence, KS: Price systems.

Edwards, J. B. (1975). The application of a system design model to the development and testing of computer-based simulations in civil procedure. Unpublished doctoral dissertation, University of Iowa, Iowa City.

Edwards, J., Norton, S., Taylor, S., Weise, M., \& Dusseldorp, R. (1975). How effective is CAI? A review of the research. Educational Leadership, 33, 147-153.

Ehrhardt, H. B. (1983). Utilization of cognitive style in the clinical laboratory sciences. American Journal of Medical Technology, 49, 569-577.

Farr, B. J. (1971). Individual differences in learning: Predicting one's more effective learning modality. Dissertation Abstracts International, 32, $13321 \mathrm{~A}$. (University Microfilms No. 71-20,355)

Freeley, M. E. (1984). Learning style and computers: Do they mesh? Early Years, 14 (8), 63, 68 .

Friedman, P., \& Alley, R. (1984, Winter). Learning styles: Applying the principles. Theory Into Practice, $\underline{23}$ (1), 77-81.

Gaston, S. (1988). Knowledge, retention, and attitude effects of computer-assisted instruction. Journal of Nursing Education, 27, 30-33.

Gregorc, A. F. (1979a). Learning/teaching styles: Potent forces behind them. Educational Leadership, 36, 234236. 
Gregorc, A. F. (1979b). Learning/teaching styles: Their nature and effects. Reston, VA: National Association of Secondary Principals.

Henson, K. T., \& Borthwick, P. (1984). Matching styles: A historical look. Theory Intro Practice, 23 (1), 3-9.

Hill, J., \& Nunney, D. N. (1974). Personalizing education programs utilizing cognitive style mapping. Bloomfield Hills, MI: Oakland Community College.

Hodges, H. (1985). An analysis of the relationships among preference for formal/informal design, one element of learning style, academic achievement, and attitudes of seventh and eighth grade students in remedial mathematics classes in a New York city alternative junior high school. Unpublished doctoral dissertation, st. John's University, Brooklyn.

Hoffer, E. P., Mathewson, H. O., Loughrey, A., \& Barnett, G. o. (1975). Use of computer-aided instruction in graduate nursing education: A controlled trial. Journal of Emergency Nursing, 1 (2), 27-29.

Huch, M. (1981). Adult students' locus of control, learning styles and satisfaction with the baccalaureate nursing program. Unpublished doctoral dissertation, University of Mississippi, University.

Huckabay, L. M. , Loucine, D. Anderson, N., Holm, D. M. , \& Lee, J. (1979). Cognitive, affective and transfer of learning consequences of computer-assisted instruction. Nursing Research, 28, 228-233.

Hunt, D. E. (1979) . Learning style and student needs: An introduction to conceptual level. In J. Keefe (Ed.), student learning styles: Diagnosing and prescribing programs (pp. 27-38). Reston, VA: National Secondary School Principals.

Jamison, D., Suppes, P., \& Wells, S. (1974). The effectiveness of alternative instructional media: A survey. Review of Educational Research, 44, 1-61.

Kaley, S. B. (1977) . Field dependence/independence and learning styles in sixth grades (Doctoral dissertation, Hofstra University, 1977). Dissertation Abstracts International, 38, 1301A.

Kearsley, G., Hunter, B., \& Seidel, R. J. (1983) . Two decades of research: What have we learned? Alexandria, VA: Human Resources Research Laboratory. 
Keefe, J.W. (1982). Assessing student learning styles: An overview. Student Learning styles and Brain Behavior (pp. 43-53). Reston, VA: National Association of secondary school Principals.

Kerr, c. (1976). Education tomorrow: For whom? Why? Address presented to the Western Regional Assembly of the College Entrance Examination Board, San Diego, CA.

Kirby, P. (1979) . Cognitive style, learning style and transfer skill acquisition (Information Series No. 195) - Columbus, OH: Ohio State University National Center for Research in Vocational Education. (ERIC Document Reproduction Service No. ED 186 685)

Kirchoff, K. T., \& Holzemer, W. (1979). Student learning and a computer-assisted instructional program. Journal of Nursing Education, 18, 22-30.

Kolb, D. A. (1986). Learning style inventory: Technical manual. Boston: McBer and Company.

Krimsky, J. (1982). A comparative study of the effects of matching and mismatching fourth grade students with their learning style preference for the environmental element of light and their subsequent reading speed and accuracy scores. (Doctoral dissertation, st. John's University, 1982). Dissertation Abstracts International, 43, 66A.

Kroon, D. (1985). An experimental investigation of the effects on academic achievement and the resultant administrative implications of instruction, congruent and incongruent with secondary industrial arts students' identified learning style perceptual preferences. Unpublished doctoral dissertation, st. John's University, Brooklyn.

Kulik, J.A. (1973) . Synthesis of research on computerbased instruction. Educational Leadership, 41 (9), 19-21.

Kulik, J. A., Bangert, R. L., \& Williams, G. (1983). Effects of computer-based teaching on secondary school students. Journal of Educational Psychology, 75, 1926 .

Kulik, J. A., \& Jaksa, P. (1977). A review of research on PSI and other educational technologies in college teaching (CRLT Report No. 10). Ann Arbor, MI: Center for Research on Learning and Teaching. 
Kulik, J. A., Kulik, C. C., \& Cohen, P. A. (1980) . Effectiveness of computer-based college teaching: A metaanalysis of findings. Review of Educational Research, 50, 525-524.

Laschinger, H. K. , \& Boss, w. (1984) . Learning styles of nursing students and career choices. Journal of Advanced Nursing, 9 , 375-380.

Lynch, P. (1981). An analysis of the relationships among academic achievement, attendance, and the individual class time preference of eleventh and twelfth grade students identified as initial or chronic truants in a suburban New York school district (Doctoral dissertation, st. John's University, 1987). Dissertation Abstracts International, 42, 1880A.

MacMurren, H. (1985). A comparative study of the effects of matching and mismatching sixth grade students with their learning style preference for the physical element of intake and their subsequent reading speed and accuracy scores and attitude. Unpublished doctoral dissertation, st. John's University, Brooklyn.

Marcinek, M. A. (1983). An analysis of learning style of RN students, BSN students and nurse educators in a baccalaureate nursing program. Unpublished doctoral thesis, West Virginia University, Morgantown.

Martini, M. (1986). An analysis of the relationship(s) between and among computer-assisted instruction, learning style perceptual preferences attitudes, and the science achievement of seventh grade students in a suburban New York school district. Unpublished doctoral disseration, st. John's University, Brooklyn.

Mckeachie, w. J. (1967). Research in teaching. In C. B. T. Lee (Ed.), Improving college teaching (pp. 215220). Washington, DC: American Council on Education.

Millerick, W. (9183) Compensating for the cognitive differences of individual learners enrolled in the various academic disciplines within a business school curriculum. Journal of Computer-Based Instruction, 9 , 144-151.

Murphy, M. A. (1987) . Preparing faculty to use and develop computer-based instructional material in nursing. Computers in Nursing, 5, 59-64. 
Murrain, P. G. (1983). Administrative determinations concerning facilities utilization and instructional grouping: An analysis of the relationship(s) between selected thermal environments and preferences for temperature an element of learning style as they affect word recognition scores of secondary students. Unpublished doctoral dissertation, st. John's University, (Brooklyn).

Murray, C. A. (1980). The comparison of learning styles between low and high reading achievement subjects it the seventh and eighth grades in a public middle school. Dissertation Abstracts International, 41, 1005A. (University Microfilms No. 80-19,053)

National Task Force. (1983, Summer). The National Task Force defines learning style operationally and conceptually. Learning styles Network Newsletter, 4 (2), 1 .

Olivieri, P., \& Sweeney, M. A. (1980). Evaluation of clinical learning by computer. Nurse Educator, 5 (4), 26-30.

Partridge, R. (1983). Learning styles: A review of selected models. Journal of Nursing Education, 22, 243248.

Perrin, J. (1982). An experimental investigation of the relationships among the learning style sociological preferences of gifted and normal primary children, selected instructional strategies, attitudes, and achievement in problem solving and word recognition. Unpublished doctoral dissertation, St. John's University (Brooklyn).

Pizzo, J. (1981). An investigation of the relationships between selected acoustic environments and sound, an element of learning style, as they affect reading achievement of male and female sixth grade students (Doctoral dissertation, St. John's University, 1981). Dissertation Abstracts International, 42, $2475 \mathrm{~A}$.

Polit, D. F., \& Hungler, B. P. (1983). Nursing research: Principles and methods. Philadelphia: J. B. Lippincott.

Price, G., Dunn, R., \& Dunn, K. (1985). Learning style inventory manual. Lawrence, KS: Price Systems.

Price, G. E., Dunn, R., \& Dunn, K. (1982). Productivity environmental preference manual. Lawrence, KS: Price Systems, Inc. 
Ramirez, M., \& Castaneda, A. (1974) - Cultural democracy, bi-cognitive development and education. New York: Academic Press.

Rappaport, P., \& Savard, G. (1980). Topic summary report: Computer-assisted instruction. Research on school effectiveness project. Portland, OR: Northwest Regional Educational Laboratory.

Reed, R. C., Collart, M. E., \& Ertel, P. Y. (1972) . Computer-assisted instruction for continued learning. American Journal of Nursing, 72, 2,035-2, 039.

Schleutermann, J. A., Holzemer, พ. L., \& Farrand, L. (1983). An evaluation of paper-and-pencil and computer-assisted simulations. Journal of Nursing Education, 22, 315-323.

Schmeck, R., Ribich, F. \& \&amanaiah, N. (1977) . Development of a self report inventory for assessing individual differences in learning processes. Applied Psychological Measurement, 1, 413-431.

Schwartz, B., \& Jackson, S.B. (1980). Computation competency. Nursing and Health Care, $1,245-248$.

Seidman, M. N. (1983). student nurse learning styles based on experiential learning theory from 3 types of nursing programs. Unpublished doctoral dissertation, West Virginia University, Morgantown.

Shea, T. C. (1983). An investigation of the relationships among preference for the learning style element of design, selected instructional environments, and reading achievement of ninth grade students to improve administrative determinations concerning effective educational facilities. Unpublished doctoral dissertation, st. John's University, Brooklyn.

Smith, L. H., \& Renzulli, J. S. (1984). Learning style preferences: A practical approach for classroom teachers. Theory Into Practice, 23 (1), 44-50.

Swartz, w. (1980). Education in the classroom. Journal of Higher Education, 51, 235-245.

Sumida, S. W. (1972). A computerized test for clinical decision making. Nursing Outlook, 20, 458-461. 
Thomas, D. G. (1978). The effectiveness of computerassisted instruction. Alaska telecommunications project. Portland, OR: Northwest Regional Educational Laboratory.

Thomas, D. B. (1978). The effectiveness of computerassisted instruction. Alaska telecommunications project. Portland, OR: Northwest Regional Educational Laboratory.

Timpke, J., \& Janney, C. P. (1981). Teaching drug dosages by computer. Nursing outlook, 29, 376-377.

Urbschat, K. S. (1977). A study of preferred learning modes and their relationships to the amount of recall of CVC trigrams. Dissertation Abstracts International, 38, 2536A. (University Microfilms No. 7724,029 )

Valish, A V., \& Boyd, J. J. (1969). The role of computerassisted instruction in continuing education of registered nurses: An experimental study. Journal of Continuing Education in Nursing, $6,13-32$.

Vinsonhaler, J. F., \& Bass, R. K. (1972). A summary of ten major studies on CAI drill and practice. Educational Technology, 12 (7), 29-32.

Virostko, J. (1983). An analysis of the relationships among academic achievement in mathematics and reading, assigned instructional schedules, and the learning style time preferences of third, fourth, fifth and sixth arade students. Unpublished doctoral dissertation, st. John's University, Brooklyn.

Wingo, L. H. (1980). Relationships among locus of motivation, sensory modality and grouping preferences of learning styles to basic skills test performance in reading and mathematics. Dissertation Abstracts International, 41, 2923A. (University Microfilms No. 81-01,803)

Wheeler, R. (1980). Teaching reading according to students' perceptual strengths. Kappa Delta Pi Record, 17 (2), 59-63.

Wheeler, R. (1983). An investigation of the degree of academic achievement evidenced when second qrade, learning disabled students perceptual preferences are matched and mismatched with complementary sensory approaches to beginning reading instruction. Unpublished doctoral dissertation, st. John's University, Brooklyn. 
White, R. (1981). An investigation of the relationships between selected instructional methods, and selected elements of emotional learning style based upon student achievement in seventh grade social studies (Doctoral dissertation, st. John's University, 1981). Dissertation Abstracts International, 42, 995A.

wilson, R. (1980). The effectiveness of computer-assisted instruction: A survey of the research. Computer technology program. Portland, OR: Northwest Regional Educational Laboratory. 
APPENDIX A

PRODUCTIVITY ENVIRONMENTAL PREFERENCE SURVEY 


\section{PLEASE NOTE:}

Copyrighted materials in this document have not been filmed at the request of the author. They are available for consultation, however, in the author's university library.

These consist of pages:

$130-131$

133-135

137

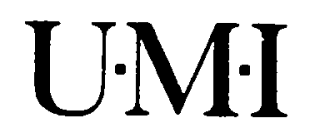


APPENDIX B

ATTITUDE TOWARDS CAI SEMANTIC DIFFERENTIAL SCALE 
APPENDIX C

SCORING TOTAL AND SUBSCALES OF THE ATTITUDE TOWARD CAI TOOL 
APPENDIX D

STUDENT RESPONSES TO AN OPEN ENDED QUESTION ASKING THEM TO DESCRIBE THEIR EXPERIENCE WITH CARDIAC EXAM BINGO COMPARED TO PREVIOUS EXPERIENCES WITH THE USE OF A COMPUTER PROGRAM AS PART OF A CLASS 
Student responses to an open ended question asking them to describe their experience with Cardiac Exam Bingo compared to previous experiences with the use of a computer program as part of a class.

1. This was easier.

2. This was an enjoyable although I didn't know enough of the answers--heart sounds. It helped me realize what I did not know, rather than quiz me on what I already know.

3. Computer class was pertinent to using computer and everyone had their own. The computers for nursing are almost always being used by someone else which takes time away from studying.

4. In physics, we did certain problems on the computer. The cardiac bingo game was more straightforward and easier.

5. Not enough questions. Not enough good questions.

6. Dosecalc, both good experiences, helpful.

7. This was a learning process, the other was a nutritional analysis survey program.

8. Programming is different than using a program and just letting it take you along as you walk through it.

9. Really enjoyed practical application rather than just writing papers.

10. Instructions not as easy to follow. 
11. Previous experience involved programming, whereas this bingo game involved merely utilizing a program for one's benefit.

12. About the same.

13. This program seemed more simplistic than previous programs.

14. Easy to do bingo game compared to my previous experience.

15. I have used Apple programs and IBM compatible software. The big difference is that they are menu and screen driven.

16. It was part of a computer class--it was new and difficult.

17. Used DoseCalc in 255 . Liked this program much better-more interesting! Relates directly to questions we might be asked.

18. Dosecalc was helpful.

19. Reinforced learning.

20. 10th grade math--I did a small program.

21. This program is simplistic comparatively.

22. This was more teaching oriented whereas the program at OSU was for analyzing data in food nutrition.

23. Used for a computer class.

24. Dosecalc was time consuming but helpful. 
25. Not as part of a class but I've done self teaching programs to learn word processing before and they were more straight forward than this one.

26. Both were fun--I'm a visual learner.

27. This was a lot easier than the project done for my nutrition class. Cardiac Bingo was more explicit.

28. They were both pleasant and very helpful.

29. This one was a lot nicer.

30. This is not as complex as the other programs.

31. Both good experiences.

32. Similar, Dosecalc was more beneficial.

33. This program was fairly easy to understand and operate.

34. It was a good learning experience as was this experience.

35. Medical terminology class was my first experience. It was very positive, a good learning experience. I found it helped prepare me for exams.

36. This program was easier to use.

37. The others were more diverse.

38. About the same. 


\section{APPENDIX E}

STUDENT RESPONSES TO THE REQUEST FOR ADDITIONAL COMMENTS ON THE ATTITUDE SURVEY 
Student responses to the request for additional comments on the attitude survey.

The Computer Program Cardiac Fxam Bingo

1. I would utilize the computer more if the questions were more relevant to the tests.

2. Like to see more representation of other cardiac problems. I played three games and questions were all very similar.

3. Need to have multiple screens with varying questions, more so than the three screens that I saw. Make sure that the review is pertinent and information learned will reflect on testing format.

4. Would appreciate a wider variety of questions.

5. More and different questions.

6. It would be more helpful to have a list out of the questions missed at the end of the game. Try to have more new questions on each game.

7. I would like to see an expanded version.

8. Clever game.

9. I would be interested in more questions being available and perhaps worded differently. overall, the program was helpful.

10. There is no way this program can cover everything we are asked to know, so I would do better reading my notes and book.

11. This would help for all of the systems. 
12. Need more variation in the tests. May return when I have more time.

13. It would help if the questions would change instead of the same question in a different game.

14. Good program.

The Use of Computers for Education

1. Just for a study aid for those who want to use it as a supplement.

2. If, as students, we had more time, this would be an enjoyable learning tool. However, my time is so limited that I feel too much pressure to sit still and enjoy.

3. I think it is fine but it should be an option not required.

4. I think this is a good idea for someone who has spare time, but I wouldn't encourage mandatory use of the computer.

5. I don't feel it should be required although it is good to have available as a study tool and should be encouraged.

6. This is an excellent way to test my knowledge of the material and identify areas I need to work on. It's like a "self test." Easy to use. 
7. Because of time limits (theirs i.e. computer $l a b$ and mine) to make it required would be a mistake, but to offer for extra help is a good idea. Thanks.

8. I would like to see more incorporated but not added to our present load.

9. Good approach. It challenges us to questions that we wouldn't normally see until exam time.

10. I believe it is an excellent tool to have available, but that it should be optional because of people having so many different ways of learning.

11. I would like computer-assisted education if it had a little better technical writing and taught me more as I went along instead of just testing what I already know or don't know.

12. Beats the heck out of reading and rereading.

13. I think the concept is worthwhile but each game should be different.

The Facilities (Instructional Media Degartment)

1. Programs are for the Apple IIe and there aren't that many Apples in the IMD. This caused some congestion at the terminals and time-wasting discussions and waiting for one's turn.

2. Too hard to use computer lab.

3. Would like to see software available for checking out of library to use at home. 


\section{Affective Comments about Personal Learning}

1. I benefitted more from the program than I thought I would. I am more interested in computerized instruction than I was before using it.

2. Learned a lot--thought it was fun.

3. Thanks.

4. I like it.

5. The computer is much more enjoyable than sitting at home reading and rereading your notes.

6. This was a nice change.

7. I enjoyed the computer, but it is not my most effective way of learning.

8. Fun.

9. I enjoy using Cardiac Bingo and wish our tests could be set up in this structure. It is fun. Thanks.

10. Cardiac Bingo was helpful but I learn better in other ways.

11. Fun!

12. Enjoyed very much!

13. I really like it.

14. I prefer computer learning.

15. I really enjoyed working on the computer. I believe the game improved my knowledge of the heart etc. Thanks.

16. Very beneficial.

17. I will never enjoy looking at a computer screen. 